Portland State University

PDXScholar

$1-4-2021$

\title{
Numerical Simulation of Continuous Cone Penetration and Interpretation of CPTu Dissipation Tests
}

Andrew Phillip Eugene Huffman

Portland State University

Follow this and additional works at: https://pdxscholar.library.pdx.edu/open_access_etds

Part of the Civil Engineering Commons, and the Geotechnical Engineering Commons Let us know how access to this document benefits you.

\section{Recommended Citation}

Huffman, Andrew Phillip Eugene, "Numerical Simulation of Continuous Cone Penetration and Interpretation of CPTu Dissipation Tests" (2021). Dissertations and Theses. Paper 5639.

https://doi.org/10.15760/etd.7511

This Thesis is brought to you for free and open access. It has been accepted for inclusion in Dissertations and Theses by an authorized administrator of PDXScholar. Please contact us if we can make this document more accessible: pdxscholar@pdx.edu. 
Numerical Simulation of Continuous Cone Penetration and Interpretation of CPTu

Dissipation Tests

by

Andrew Phillip Eugene Huffman

A thesis submitted in partial fulfillment of the requirements for the degree of

Master of Science

in

Civil and Environmental Engineering

Thesis Committee:

Diane M. Moug, Chair

Arash Khosravifar

Annette Dietz

Portland State University

2020 
(C) 2020 Andrew Phillip Eugene Huffman 


\begin{abstract}
The piezocone penetration test (CPTu) is a commonly used method of geotechnical site investigation. The CPTu is especially useful because it provides a nearly continuous data profile of in-situ soil behavior, which can be correlated to useful engineering parameters. However, limitations exist for interpretation of geotechnical properties from CPTu data and for numerical analysis of cone penetration problems. The research presented in this thesis examines interpretation of coefficient of consolidation from CPTu dissipation test data and implementation of an algorithm to advance numerical simulation of cone penetration problems.
\end{abstract}

This thesis presents analysis of CPTu dissipation responses from field-measured and numerically simulated dissipation tests and their interpretation, according to four published methods. The performance of these methods in interpreting assigned model properties is examined under various conditions of vertical and horizontal hydraulic conductivities and OCR. The analysis indicates that existing methods of interpreting coefficient of consolidation from dissipation tests fall short in two areas-improper interpretation of non-monotonic dissipation and inaccurate neglect of the role of vertical pore pressure migration during dissipation testing.

A useful tool in studying CPTu site investigation and dissipation testing is high quality numerical simulation of CPTu testing. Moug (2017) described an ALE model for steady-state simulation of cone penetration at a single depth using the MIT-S1 constitutive model, which accurately represents clayey and silty behavior well, including anisotropic 
loading of clay. This is especially important because of the complex anisotropic stress conditions that exist around the cone (Moug, et al. 2019). However, due to its remeshing step, the Moug (2017) model is limited to simulation of a single soil layer at a single depth. This thesis describes the implementation and verification of a linear elastic finite-element adaptive remeshing algorithm that, when integrated with the Moug (2017) model, provides a numerical scheme capable of simulating penetration through depth in a soil profile, while retaining the valuable constitutive performance of the original model. 


\section{Acknowledgements}

I would like to express my gratitude to my advisor, Professor Diane Moug. Without her, I would not have thought myself capable of succeeding in this master's program or working as a research assistant. She opened the door to those opportunities for me, and she has provided invaluable guidance and assistance throughout my time in the geotechnical engineering graduate program. I am very appreciative of her patience and encouragement as I worked through new topics and methods and her support for my interests and career goals outside of our research.

Thank you to Dr. Khosravifar for first sparking my interest in geotechnical engineering through his Introduction to Seismology and Site Evaluation course. I have enjoyed all his courses that I have taken and his effective teaching style

Throughout my graduate program I have appreciated the contributions of fellow students who enhanced and supported my experience. They provided encouragement and boosted morale through collaboration on coursework, discussions of research objectives and challenges, and occasional food items.

Also, I would like to thank my family and friends who have supported and encouraged me along the way. Thank you all for your interest, albeit of varying degrees, in my research endeavors. Your confidence in me has been very meaningful.

Finally, I would like to acknowledge the financial support of the National Science Foundation (award CMMI-1927557). Any opinions, findings, and conclusions or recommendations expressed in this material are those of the author and do not necessarily reflect the views of this agency. 


\section{Table of Contents}

$\begin{array}{lll}\text { ABSTRACT } & \text { i }\end{array}$

ACKNOWLEDGEMENTS iii

LIST OF TABLES V v

LIST OF FIGURES vi

CHAPTER 1 (INTRODUCTION) 1

CHAPTER 2 (INTERPRETATION OF SIMULATED AND FIELD-MEASURED NON-MONOTONIC CPTU DISSIPATION TESTS)

CHAPTER 3 (LINEAR ELASTIC FINITE-ELEMENT REMESHING

ALGORITHM)

CHAPTER 4 (CONCLUSIONS AND FUTURE WORK)

REFERENCES 


\section{List of Tables}

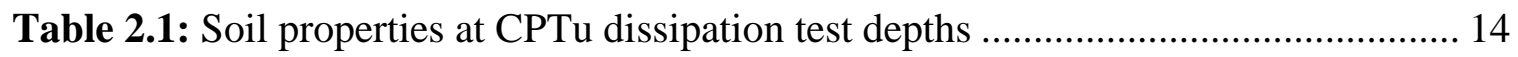

Table 2.2: Summary of $\mathrm{t}_{\max }, \mathrm{t}_{50}, \mathrm{t}_{50, \mathrm{c}}$ values for each Sunderland dissipation test .......... 15

Table 2.3: Summary of field dissipation test interpreted $c_{h}$ values............................... 18 


\section{List of Figures}

Figure 1.1: Diagram of CPT measurements ............................................................... 1

Figure 1.2: Typical CPT profiles from DeGroot and DeJong (2012)............................... 2

Figure 1.3: Example of monotonic and nonmonotonic dissipation curves (after Whittle et

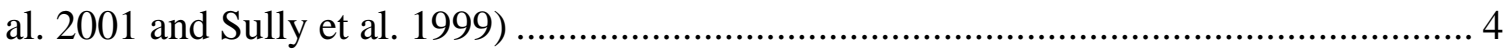

Figure 1.4: Illustration of Lagrangian, remeshing, and Eulerian steps. This thesis describes implementation of an algorithm for adaptive remeshing.................................. 5

Figure 2.1: Stress-strain curves from CIUC single-element simulations for Boston blue

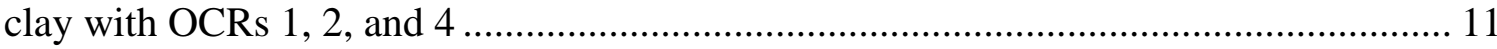

Figure 2.2: Sunderland site description (after Moug et al. 2020) …………….............. 12

Figure 2.3: Measured CPTu data at the Sunderland site................................................ 13

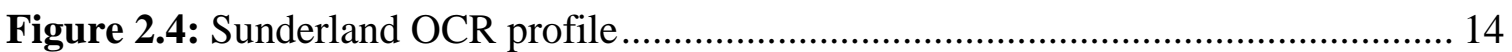

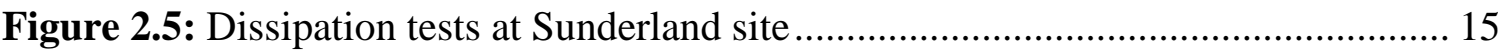

Figure 2.6: $\mathrm{B} \& \mathrm{M}$ fit interpretation at $2.5 \mathrm{~m}$ depth......................................................... 16

Figure 2.7: $\mathrm{B} \& \mathrm{M}$ fit interpretation at $4.0 \mathrm{~m}$ depth....................................................... 17

Figure 2.8: B\&M fit interpretation at $5.6 \mathrm{~m}$ depth....................................................... 17

Figure 2.9: CPTu model geometry and boundary conditions ......................................... 19

Figure 2.10: Excess pore pressure for OCR values 1, 2, and 4 ................................... 22

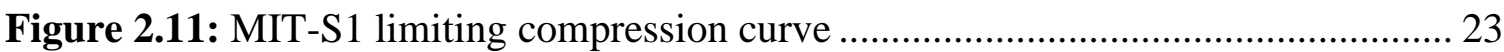

Figure 2.12: $c_{h, \text { interp }}$ vs. $c_{h, \text { model }}$ for the four interpretation methods ................................. 24

Figure 2.13: Comparison of interpreted $c_{h}$ values to model $c_{h}$ values using different

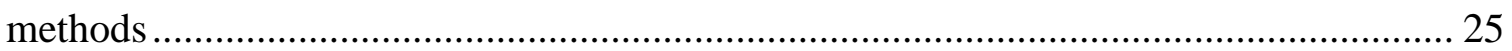

Figure 3.1: Example of CPT-measured site profile ………………….......................... 29 
Figure 3.2: Schematic illustrating the ALE algorithm with adaptive remeshing 30

Figure 3.3: Example finite-element mesh with 10 nodes

Figure 3.4: Comparison of undeformed grid coordinates and deformed (by unconfined axial compression) grid coordinates, obtained by solution in FLAC and the remeshing finite-element solution ................................................................................. 35

Figure 3.5: Comparison of undeformed grid coordinates and deformed (by radial compression) grid coordinates, obtained by solution in FLAC and the remeshing finiteelement solution 36 


\section{List of Abbreviations}

$a$

cone radius

ALE

Arbitrary Lagrangian Eulerian

ASTM

American Society for Testing and Materials

$\mathrm{BBC}$

Boston blue clay

bgs

below ground surface

$c_{h}$

horizontal coefficient of consolidation

$c_{h, \text { model }}$

model horizontal coefficient of consolidation

$c_{h, \text { interp }}$

interpreted horizontal coefficient of consolidation

CIUC

Isotropically Consolidated Undrained Triaxial Compression

CPT

cone penetration test

$\mathrm{CPTu}$

piezocone penetration test

$D$

constrained modulus

$\Delta e$

change in void ratio

$\Delta \varepsilon_{v}$

change in vertical strain

$\Delta \sigma_{v}$

change in vertical stress

$\Delta u$

excess pore pressure

$\left(\Delta u_{o c t}\right)_{i} \quad$ octahedral-induced initial excess pore pressure

$\left(\Delta u_{\text {shear }}\right)_{i} \quad$ shear-induced initial excess pore pressure

$\Delta u_{2, \text { initial }} \quad$ initial $\mathrm{u}_{2}$ excess pore pressure

$\Delta u_{2, \text { peak }} \quad$ peak $\mathrm{u}_{2}$ excess pore pressure

$\epsilon$

strain vector

$e_{0}$

initial void ratio

$f$

sleeve friction

FLAC

Fast Lagrangian Analysis of Continua

$G$

vector of boundary displacement

$G_{50}$

shear modulus at $50 \%$ of peak strain

viii 


\begin{tabular}{|c|c|}
\hline$K$ & stiffness matrix \\
\hline$K_{b u l k}$ & bulk modulus \\
\hline$I_{c}$ & soil behavior type index \\
\hline$I_{R}$ & rigidity index \\
\hline$k_{h}$ & horizontal hydraulic conductivity \\
\hline$k_{v}$ & vertical hydraulic conductivity \\
\hline$M$ & slope of the critical state line \\
\hline$v$ & Poisson's ratio \\
\hline OCR & overconsolidation ratio \\
\hline$p$ & force vector \\
\hline PSU & Portland State University \\
\hline$q_{c}$ & cone tip resistance \\
\hline$\sigma$ & stress vector \\
\hline SBT & soil behavior type \\
\hline$S_{u}$ & undrained shear strength \\
\hline$\sigma_{p}^{\prime}$ & pre-consolidation stress \\
\hline$\sigma_{V O}^{\prime}$ & initial vertical effective stress \\
\hline$T^{*}$ & modified time factor \\
\hline$t$ & time \\
\hline$t_{50}$ & time corresponding to $50 \%$ dissipation \\
\hline$t_{50 c}$ & adjusted $t_{50}$ according to Chai et al. (2012) \\
\hline$t_{50}$ & adjusted t50 according to Sully et al. (1999) \\
\hline$t_{\max }$ & time corresponding to maximum pore pressure \\
\hline$t_{\text {peak }}$ & time corresponding to peak pore pressure \\
\hline$t_{u \max }$ & time corresponding to peak pore pressure \\
\hline$u_{1}$ & pore pressure measured at cone face \\
\hline$u_{2}$ & pore pressure measured at cone shoulder \\
\hline
\end{tabular}


USCS Unified Soil Classification System

$x \quad$ displacement vector 


\section{Chapter 1 (Introduction)}

The piezocone penetration test (CPTu) is a commonly used method of geotechnical site investigation. As the instrumented cone (see Figure 1.1) advances through a soil profile, it typically measures cone tip resistance $\left(q_{c}\right)$, sleeve friction $(f)$, and pore pressure measured at the cone shoulder location $\left(u_{2}\right)$, as described in ASTM (2004). The CPTu is especially useful because it provides a nearly continuous data profile (see Figure 1.2) of these measurements.

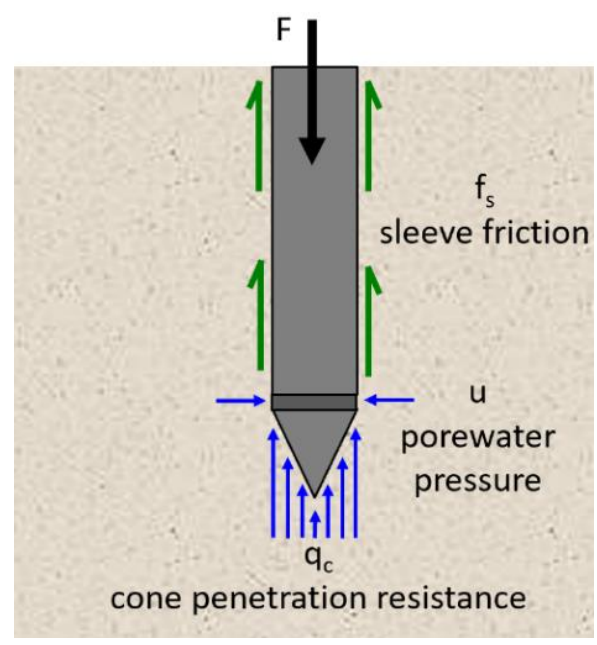

Figure 1.1: Diagram of CPT measurements 

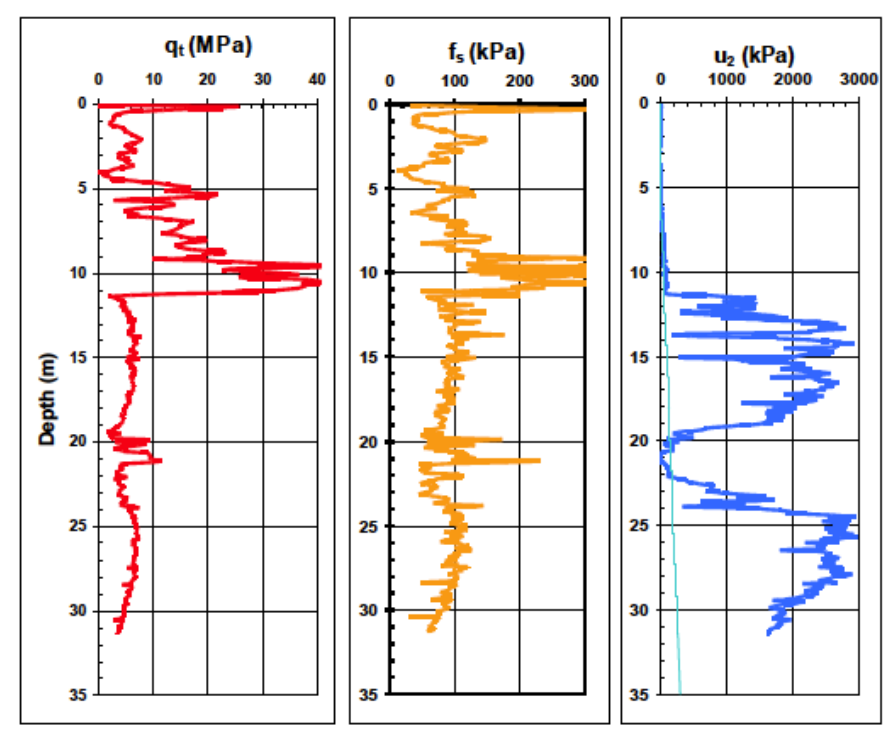

Figure 1.2: Typical CPT profiles from DeGroot and DeJong (2012)

Many relationships, theoretical and empirical, have been developed to relate $\mathrm{CPTu}-$ measured data (e.g., $\left.f_{s}, q_{c}, u_{2}\right)$ to geotechnical soil properties. For example, CPTu data can be correlated to geotechnical properties, such as undrained shear strength (e.g., Chen \& Mayne 1994), friction angle (e.g., Jamiolkowski et al. 1988), liquefaction susceptibility (e.g., Boulanger \& Idriss 2016), and preconsolidation stress (Chen \& Mayne 1994). These measurements can also be used to interpret soil type from soil behavior type (SBT) charts, as in Robertson (2009). Mayne (2007) describes standard methods for correlating CPTu measurements geotechnical properties.

However, knowledge gaps still exist, especially regarding CPTu dissipation testing. $\mathrm{CPTu}$ dissipation tests are frequently performed in engineering site investigation to characterize soil-water properties including, the coefficient of consolidation or permeability, which can be used to estimate settlement rates and seepage behavior. During 
cone penetration testing, the instrumented cone is vertically advanced at a near constant rate and excess pore water pressures are generated by the strains induced around the penetrating cone. CPTu dissipation tests are performed by pausing cone penetration and recording pore pressures at piezo-elements that are commonly at either the cone face position $\left(u_{1}\right)$ or the cone shoulder position $\left(u_{2}\right)$; during this pause in penetration, excess pore water pressures dissipate to hydrostatic conditions at a rate related to soil-water properties.

The horizontal coefficient of consolidation $\left(c_{h}\right)$ is a primary soil property estimated from CPTu dissipation tests. Several methods (e.g., Teh \& Houlsby 1991, Sully et al. 1999, Burns \& Mayne 1998, and Chai et al. 2012) of interpreting $c_{h}$ from dissipation test data exist, but each of these methods relies upon simplifying assumptions, including monotonic dissipation and/or only radial migration of pore pressure, that do not accurately reflect actual dissipation behavior. Two of the chief sources of difficulty in interpreting dissipation records are non-monotonicity of dissipation and vertical pore pressure migration since most methods assume radial (horizontal) pore pressure migration dominates the dissipation response. Figure 1.3 shows examples of both monotonic and non-monotonic CPTu dissipation response measured at the $u_{2}$ position.

Most interpretation methods assume that the response is monotonic, and there currently is no theoretical understanding of the cause of non-monotonic dissipation responses thereby making interpretation of this test type unreliable. 


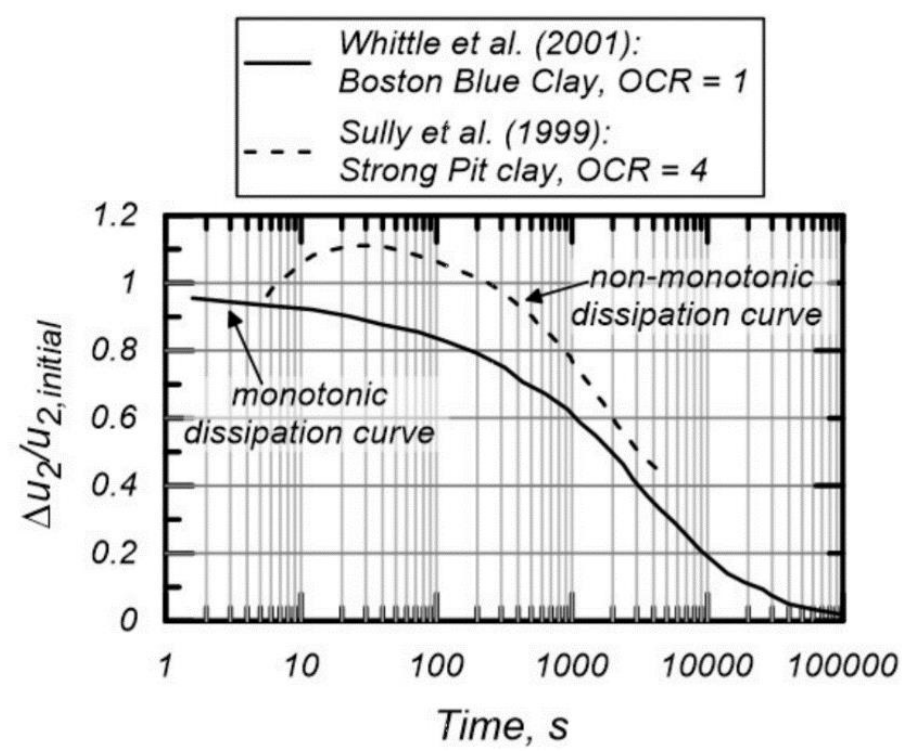

Figure 1.3: Example of monotonic and nonmonotonic dissipation curves (after Whittle et al. 2001 and Sully et al. 1999)

This thesis illustrates interpretation of dissipation records using several established CPTu dissipation interpretation methods and examines their performance in estimating modeled soil properties. Additionally, the compatibility of the assumptions and theory underlying these methods with the modeled soil behavior (both mechanical and hydraulic) is analyzed toward the end of providing insight into how interpretive approaches might be improved.

Chapter 2 of this thesis analyzes simulated CPTu dissipation responses and their $c_{h}$ values interpreted, according to several established methods. The role of vertical and horizontal pore pressure dissipation and the effect of non-monotonicity are examined.

The undrained cone penetration simulations analyzed in this thesis are numerically implemented, as described by Moug (2017), using the MIT-S1 constitutive model. MIT$\mathrm{S} 1$ is a complex constitutive model that captures clayey and silty behavior well, including 
anisotropic loading of clay. This is especially important because of the complex anisotropic stress conditions that exist around the cone (Moug, et al. 2019).

The cone penetration model, based on an Arbitrary Lagrangian Eulerian (ALE) algorithm, is a steady-state model, which simulates conditions at one depth, whereas other models simulate cone penetration continuously over a soil profile (references). ALE algorithms include three steps per simulation cycle - Lagrangian deformation, remeshing, and Eulerian remapping. This model is limited to simulation at a single depth due to its implementation of the remeshing step.

Chapter 3 of this thesis presents a finite-element adaptive remeshing step that, when integrated with the Moug (2017) model, provides a numerical scheme capable of simulating penetration through depth, while retaining the valuable constitutive performance of the original model. Figure 1.4 illustrates the role of the adaptive remeshing step in the numerical algorithm. Chapter 3 describes the implementation of the adaptive remeshing algorithm and two verification cases.
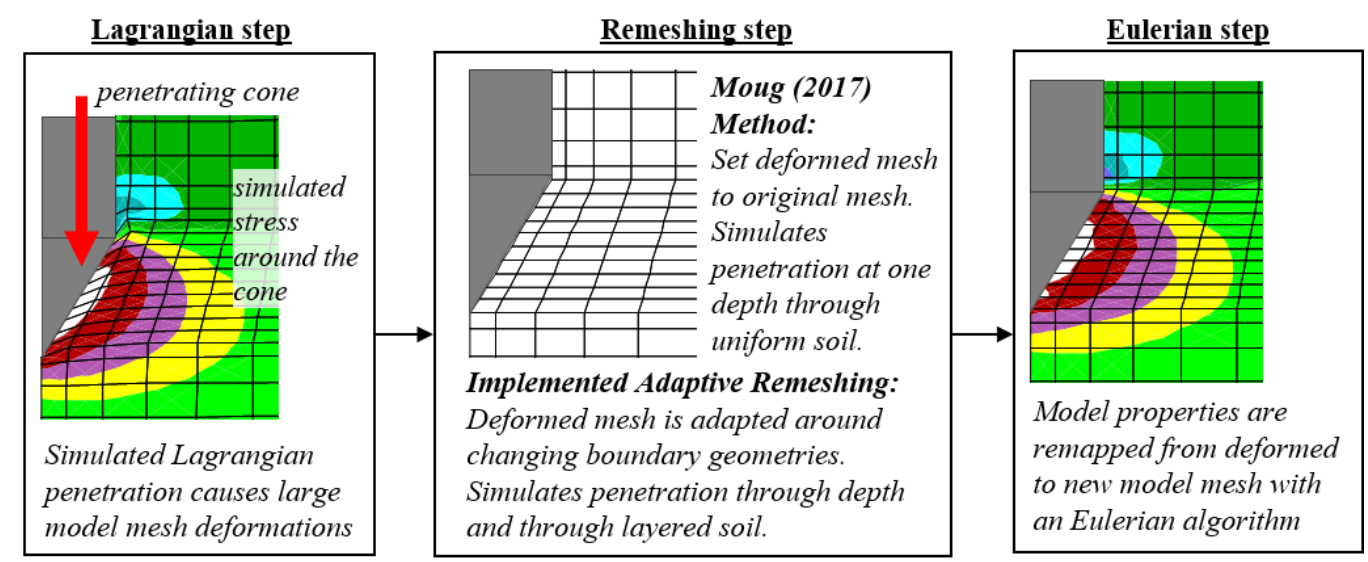

cycle to advance simulated penetration

Figure 1.4: Illustration of Lagrangian, remeshing, and Eulerian steps. This thesis describes implementation of an algorithm for adaptive remeshing. 
Chapter 2 (Interpretation of Simulated and Field-measured Non-Monotonic CPTu

$$
\text { Dissipation Tests) }
$$

\subsection{Introduction}

$\mathrm{CPTu}$ dissipation tests are frequently performed in engineering site investigation to characterize soil-water properties including, the coefficient of consolidation and permeability. During cone penetration testing, the instrumented cone is vertically advanced at a near constant rate and excess pore water pressures are generated by the strains induced around the penetrating cone. CPTu dissipation tests are performed by pausing cone penetration and recording pore pressures at piezo-elements that are commonly at either the cone face position $\left(u_{1}\right)$ or the cone shoulder position $\left(u_{2}\right)$; during this pause in penetration, excess pore water pressures dissipate to hydrostatic conditions at a rate related to soil-water properties.

The horizontal coefficient of consolidation $\left(c_{h}\right)$ is a primary soil property estimated from CPTu dissipation tests. Many interpretation methods assume that pore pressure migration is exclusively in the horizontal (radial) direction (e.g. Teh \& Houlsby 1991, Burns \& Mayne 1998, Sully et al. 1999, and Chai et al. 2012) However, there is growing understanding that drainage does not occur exclusively radially, but vertical migration of pore pressure also occurs. Vertical pore pressure migration seems to be especially significant during the early portion of non-monotonic dissipation tests due to complex stress conditions and resulting gradients that induce upward flow (Sully et al. 1999). However, there remain knowledge gaps in the role of vertical pore water pressure migration, how it affects CPTu dissipation tests and interpreted $c_{h}$ values. 
Early interpretation methods of CPTu dissipation tests were based on monotonic decay of pore pressure at the $u_{1}$ and $u_{2}$ positions (e.g., Teh \& Houlsby 1991). However, a large subset of CPTu $u_{2}$ dissipation tests record a non-monotonic response where there is an initial rise in $u_{2}$ to a peak value that then decays to static conditions (e.g. Burns \& Mayne 1998, Sully et al. 1999, and Chai et al. 2012). These non-monotonic tests are associated with highly over consolidated soils and dilatory soils. More recently published methods of interpretation have focused on accounting for such non-monotonic dissipation (e.g. Sully et al. 1999, Burns and Mayne 1998, Chai et al. 2012). However, these methods largely do not account for a reason that non-monotonic CPTu $u_{2}$ tests occur and neglect the role of vertical pore pressure migration. Furthermore, there is little understanding of how reliably various non-monotonic interpretation methods interpret $c_{h}$.

The objective of this chapter is to evaluate interpretation of $c_{h}$ from monotonic and non-monotonic $\mathrm{CPTu} u_{2}$ dissipation tests with four published interpretation methods. These methods include those that were developed for monotonic CPTu $u_{2}$ dissipation tests (Teh \& Houlsby 1991), for non-monotonic CPTu $u_{2}$ dissipation tests (Sully et al. 1999, Chai et al. 2012), and that interpret monotonic and non-monotonic CPTu $u_{2}$ dissipation tests (Burns \& Mayne 1998). First, this chapter presents CPTu dissipation tests from fieldmeasured data and from simulated tests. The field-measured non-monotonic CPTu dissipation curves are from a research site in Portland, Oregon; and with CPTu dissipation simulated with a direct axisymmetric cone penetration model with the MIT-S1 constitutive model calibrated for normally consolidated to over consolidated Boston blue clay. Then, this chapter discusses $c_{h}$ interpretation methods and how they are applied with monotonic 
or non-monotonic tests. Finally, $c_{h}$ is interpreted from the field-measured and simulated CPTu dissipation tests. The $c_{h}$ interpreted from simulated tests is compared to the modelassigned values. Additionally, the simulated results are used to examine the role of vertical excess pore pressure migration. Results from simulated CPTu dissipation tests provide insight into interpretation of the field-measured CPTu dissipation tests.

\subsection{CPTu u2 dissipation interpretation}

\section{Interpretation methods}

Dissipation tests were analyzed using four existing interpretation methods published by Teh \& Houlsby (1991), Sully et al. (1999), Chai et al. (2011), and Burns \& Mayne (1998). Each of these methods assume horizontal (radial) $\Delta u$ migration dominates the response and vertical $\Delta u$ migration is negligible. The Teh \& Houlsby (1991) interpretation assumes monotonic $u_{2}$ dissipation, while the other methods address non-monotonic dissipation. Each of these four methods were used to interpret the field dissipation tests in Figure 2.5 and the simulated dissipation tests in Figure 2.10.

The Teh \& Houlsby (1991) interpretation method (henceforth referred to as T\&H) builds upon Terazaghi-Rendulic uncoupled consolidation theory for the relationship between time and $c_{h}$. The method empirically accounts for the effect of rigidity index $\left(I_{R}\right)$ on the size of the $\Delta u$ zone that results from undrained penetration in clay. They also developed modified time factors $\left(T^{*}\right)$ corresponding to degrees of consolidation and the position on the cone where pore pressure is measured. For $50 \%$ consolidation measured at the $u_{2}$ position, $T^{*}$ is 0.245 . This method estimates $c_{h}$ with: 


$$
T^{*}=\frac{c_{h} t}{a^{2} I_{R}{ }^{0.5}}
$$

where $a$ is the cone radius and, $I_{R}$ is the soil's rigidity index $\left(G / s_{u}\right)$.

The Sully et al. (1999) method (henceforth referred to as Sully), is a modification of $\mathrm{T} \& \mathrm{H}$ and accounts for non-monotonic dissipation through a logarithm of time plot correction or a square root of time plot correction. Only the logarithm of time plot correction is discussed here. Using this correction method, the time corresponding to the peak excess pore pressure is treated as the initial time by subtracting it from the time values throughout the dissipation record. When calculating $c_{h}$ based on $t_{50}$, this method gives an adjusted value, $t_{50}$ ', from which $c_{h}$ is calculated using Equation 1. This adjusted $t_{50}$ ' is defined as $t_{50}-t_{\text {peak }}$

The Chai et al. (2012) method (Chai) is also a modification of T\&H to account for non-monotonic dissipation. It is empirical method developed from finite element modeling of cone penetration as contact problem using Mohr Coulomb and Modified Cam Clay as constitutive models. Dissipation was treated as an uncoupled consolidation problem assuming only radial drainage with initial pore pressure condition estimated from cylindrical cavity expansion theory. From their simulated results, they developed an empirical definition, shown in Equation 2.2, of the corrected time for 50\% consolidation, $t_{50 c} . c_{h}$ is estimated by Equation 2.1 using $t_{50 c}$, defined as:

$$
t_{50 c}=\frac{t_{50}}{1+18.5\left(\frac{t_{u} \max }{t_{50}}\right)^{0.67}\left(\frac{I_{R}}{200}\right)^{0.3}}
$$

where $t_{u \text { max }}$ is the time corresponding the peak pore pressure. 
Burns \& Mayne's method (B\&M), founded on spherical cavity expansion theory and Modified Cam Clay critical state soil mechanics, is an analytical solution to radial consolidation problem. The required initial condition, initial excess pore pressure, is estimated the sum of initial octahedral-induced excess pore pressure and the initial shear induced pore pressure, as shown in Equations 3 and 4, respectively. Mayne 2001 presented an approximate closed form solution, based on the same initial condition estimated by Equations 2.3 and 2.4 for the partial differential equation governing radial consolidation. This solution models dissipation over time of the two components of excess pore pressure, octahedral-induced and shear-induced, separately, as defined in Equation 2.5, where $T^{*}$ is defined by Equation 2.6., $\sigma_{v O}^{\prime}$ is the initial vertical effective stress, $M$ is the slope of the critical state line, and OCR is the ratio of pre-consolidation effect stress to current effective stress.

$$
\begin{gathered}
\left(\Delta u_{o c t}\right)_{i}=\frac{2}{3} M{\sigma^{\prime}}^{\prime}{ }\left(\frac{O C R}{2}\right)^{\Lambda} \ln \left(I_{R}\right) \\
\left(\Delta u_{\text {shear }}\right)_{i}=\sigma^{\prime}{ }_{v 0}\left[1-\left(\frac{O C R}{2}\right)^{\Lambda}\right] \\
\Delta u=\frac{\left(\Delta u_{o c t}\right)_{i}}{1+50 T^{*}}+\frac{\left(\Delta u_{\text {shear }}\right)_{i}}{1+5000 T^{*}} \\
T^{*}=\frac{c_{h} t}{a^{2}\left(I_{R}\right)^{0.75}}
\end{gathered}
$$

\section{Rigidity index}

As discussed above, $I_{R}$ is used in all four interpretation methods where it relates to the size of the $\Delta u$ field that develops during undrained cone penetration. There are several available methods for estimating $I_{R}$ : estimates of typical values, estimated from lab data, or estimates from CPTu data. When estimating $I_{R}$ from lab data, the shear modulus at $50 \%$ of peak shear 
strain, $G_{50}$, and undrained shear strength, $s_{u}$, from Isotropically Consolidated Undrained Triaxial Compression (CIUC) is typically used to represent the average response of soil around the advancing cone (Schnaid et al. 1997, Mayne 2001, and Krage et al. 2014).

For analysis of the simulated dissipation tests presented here, $I_{R}$ values were estimated from single-element FLAC simulations CIUC tests in Boston Blue Clay. Shear stress vs. shear strain curves are shown in Figure 2.1 (a)-(c) for OCRs 1, 2, and 4, respectively. $G_{50}$ and undrained shear strength, $s_{u}$, were estimated from Figure 2.1 and used to calculate the $I_{R}$ values used in interpretation of dissipation data.
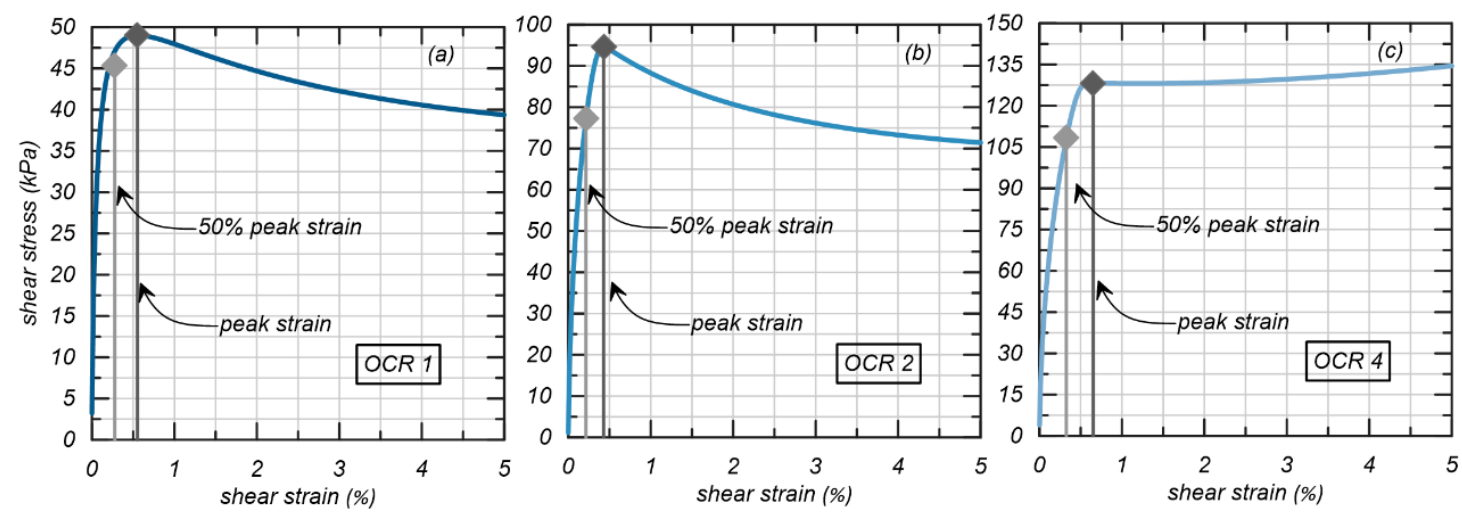

Figure 2.1: Stress-strain curves from CIUC single-element simulations for Boston blue clay with OCRs 1,2 , and 4

For analysis of the field tests presented here, $I_{R}$ values are based on monotonic direct simple shear tests that characterized a Shansep relationship for $s_{u}$ $\left(s_{u}=0.25 \sigma_{v}^{\prime} O C R^{0.75}\right)$ and $G$, defined as the secant modulus at $50 \%$ of peak shear strain, as $3250 \mathrm{kPa}$. The resulting $I_{R}$ values are presented in the following section.

\subsection{Field-measured CPTu dissipation tests}

\section{Field-measured results}


Field CPTu $u_{2}$ dissipation tests were performed in Portland, Oregon at the Sunderland research site. The CPTu dissipation tests were performed in Holocene-aged low plasticity silt deposited by the adjacent Columbia River. A summary of the site stratigraphy is shown in Figure 2.2. Soil samples for classification and characterization were obtained by handaugering, and by hollow stem auger drilling with split spoon sampling and Shelby tube sampling. The soil samples were classified with the Unified Soil Classification System (USCS) via Atterberg limits and sieve testing; additional information about site conditions and site characterization is provided in Moug et al. (2020) and Sorenson et al. (2021).

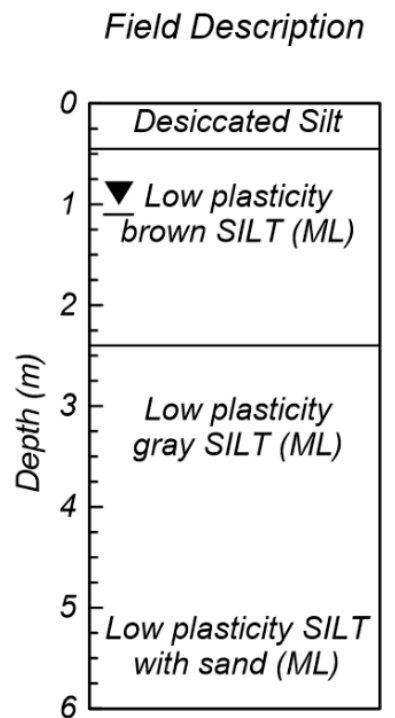

(a)

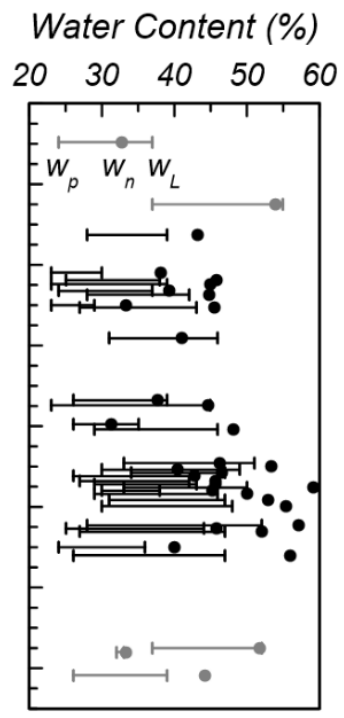

(b)

Figure 2.2: Sunderland site description (after Moug et al. 2020)

CPTu profiles were performed at the site and are shown in Figure 2.3. Interpreted SBT from the site classified the soils primarily as silty clay and clayey silt by the Robertson (2009) SBT classification, where $I_{c}$ values range from about 2.6 to 3 for depths from about $0.5 \mathrm{~m}$ to $6 \mathrm{~m}$. An interpreted OCR vs. depth profile (see Figure 2.4) was developed for the site from lab-estimated OCR values at various depths (Preciado et al. 2021) and OCR 
values estimated from CPT data. The lab-measured pre-consolidation stresses $\left(\sigma_{p}^{\prime}\right)$ were obtained from publicly available geotechnical engineering exploration reports of nearby sites (reference the reports) and oedometer tests performed at the PSU geotechnical research lab with Shelby tube samples.
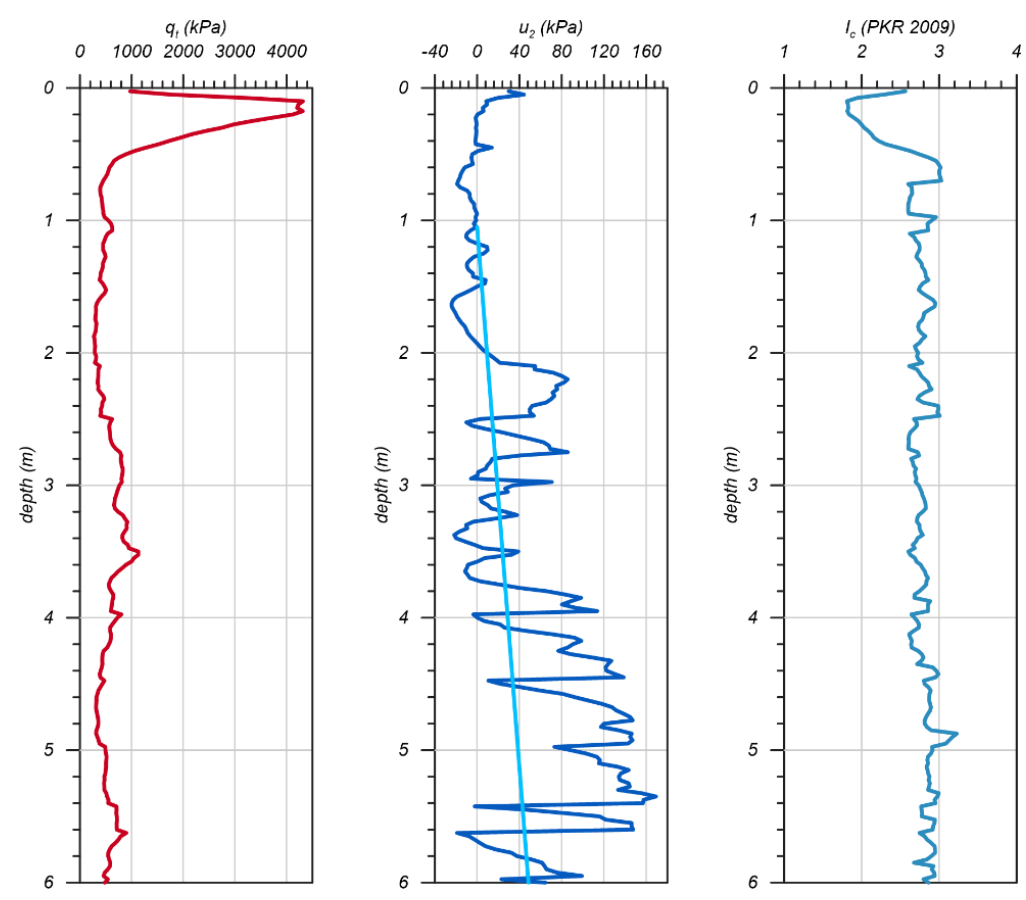

Figure 2.3: Measured CPTu data at the Sunderland site 


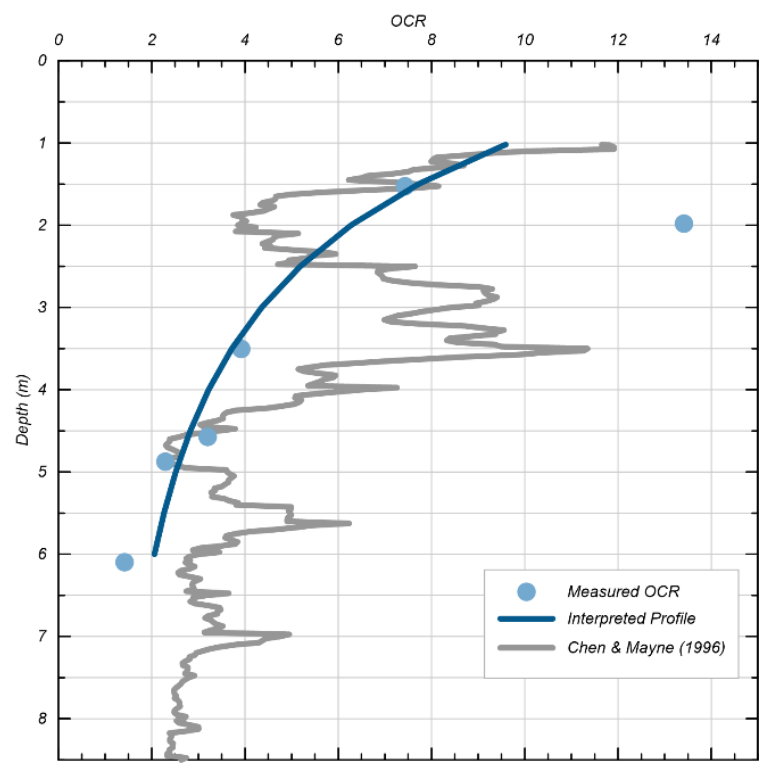

Figure 2.4: Sunderland OCR profile

Three dissipation tests were performed at the site at 2.5, 4.0, and $5.6 \mathrm{~m} \mathrm{bgs}$ which are all within the low plasticity silt unit. The estimated OCRs for the soil at these depths are 4, 3, and 2.5, respectively, based on the profile in Figure 2.4. Additional soil properties and test conditions for these depths are summarized in Table 2.1.

Table 2.1: Soil properties at CPTu dissipation test depths

\begin{tabular}{cccc}
\hline $\begin{array}{c}\text { Depth } \\
(\mathrm{m})\end{array}$ & OCR & $\begin{array}{c}\sigma^{\prime} \mathrm{v} \\
(\mathrm{kPa})\end{array}$ & $\mathrm{I}_{\mathrm{R}}$ \\
\hline 2.5 & 4 & 25 & 184 \\
4.0 & 3 & 34 & 168 \\
5.6 & 2.5 & 44.5 & 147 \\
\hline
\end{tabular}

The three dissipation traces are shown in Figure 2.5. All three tests exhibited nonmonotonic $\Delta u_{2}$ dissipation. However, the higher OCR tests exhibited a more strongly nonmonotonic response. The ratio of $\Delta u_{2, \text { peak }}$ to $\Delta u_{2, \text { initial }}$, approximately, is 2.9 for the OCR 4 test, 2.1 for the OCR 3 test, and 1.8 for the OCR 2.5 test. 


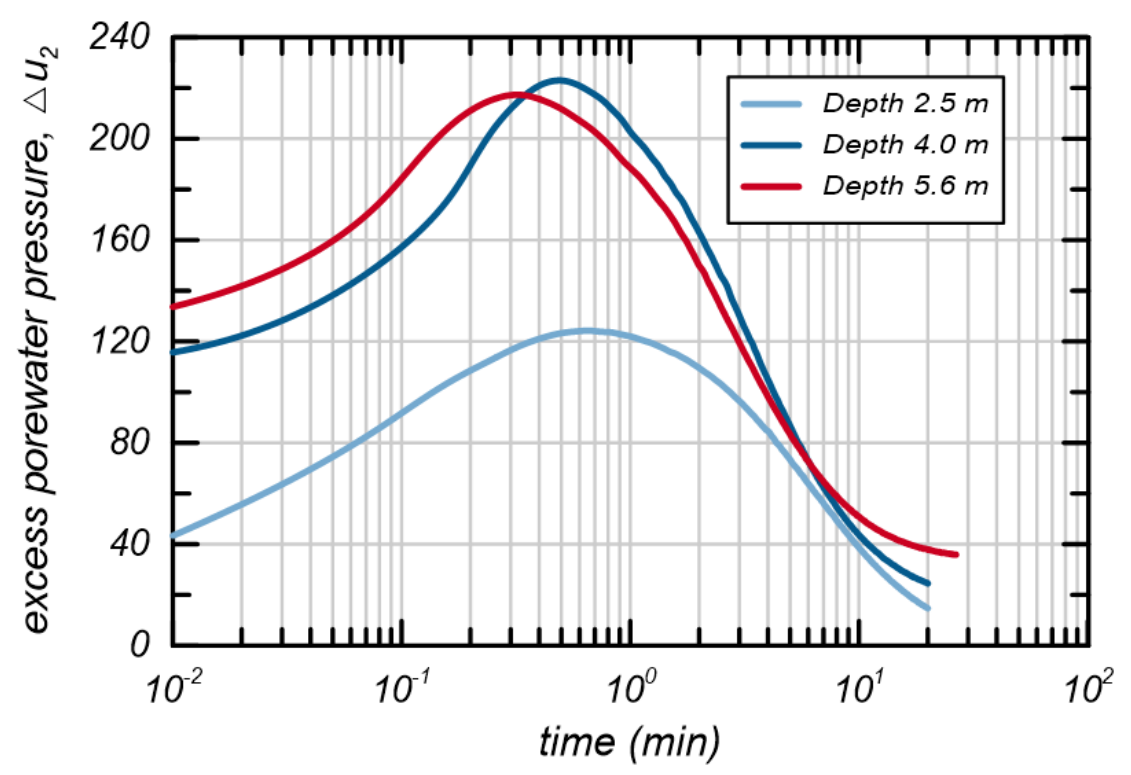

Figure 2.5: Dissipation tests at Sunderland site

\section{Interpretation of field-measured CPTu tests}

The dissipation tests shown in Figure 2.5 were interpreted using the four methods described previously- T\&H, Chai, Sully, and B\&M. The time corresponding to $50 \%$ dissipation of maximum pore pressure, $t_{50}$, time corresponding to the maximum pore pressure, $t_{\max }$, and corrected $t_{50}$ values (according to Sully and Chai) are summarized in Table 2.2. The normalized B\&M fitted dissipation curves are plotted with the normalized measured dissipation curves in Figures 2.6, 2.7, and 2.8.

Table 2.2: Summary of $t_{\max }, t_{50}, t_{50, c}$ values for each Sunderland dissipation test

\begin{tabular}{ccccc}
\hline $\begin{array}{c}\text { Depth } \\
(\mathrm{m})\end{array}$ & $\mathrm{t}_{\max }$ & $\mathrm{t}_{50}$ & $\begin{array}{c}\mathrm{t}_{50} \\
(\text { Sully }) \\
(\mathrm{s})\end{array}$ & $\begin{array}{c}\mathrm{t}_{50 \mathrm{c}} \\
(\text { Chai) } \\
(\mathrm{s})\end{array}$ \\
\hline 2.5 & 0.7 & 6.3 & 5.6 & 1.4 \\
4.0 & 0.5 & 3.5 & 3.0 & 0.69 \\
5.6 & 0.34 & 2.8 & 2.46 & 0.60 \\
\hline
\end{tabular}


Interpretation with the $\mathrm{B} \& \mathrm{M}$ method was challenging because it significantly overestimated the initial value of $u_{2}$ compared to the measured Sunderland data, which made it impossible to generate a well-fitted curve. Since the initial $u_{2}$ values could not be matched within the constraints of the model parameters, the interpretation sought to match the measured response after the peak $u_{2}$ values. The measured excess pore pressure data and the $B \& M$ excess pore pressure curves were each normalized by their maximum excess pore pressure value. Then, the normalized B\&M curve was fitted to the normalized data, as shown in Figures 2.6, 2.7, and 2.8.

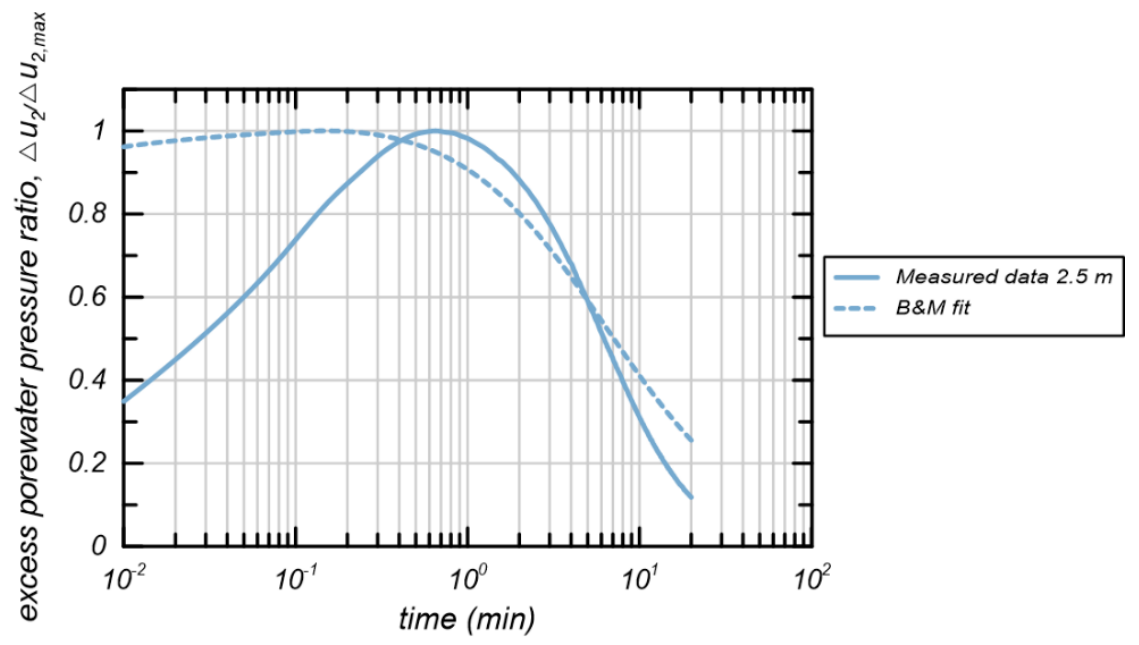

Figure 2.6: $\mathrm{B} \& \mathrm{M}$ fit interpretation at $2.5 \mathrm{~m}$ depth 


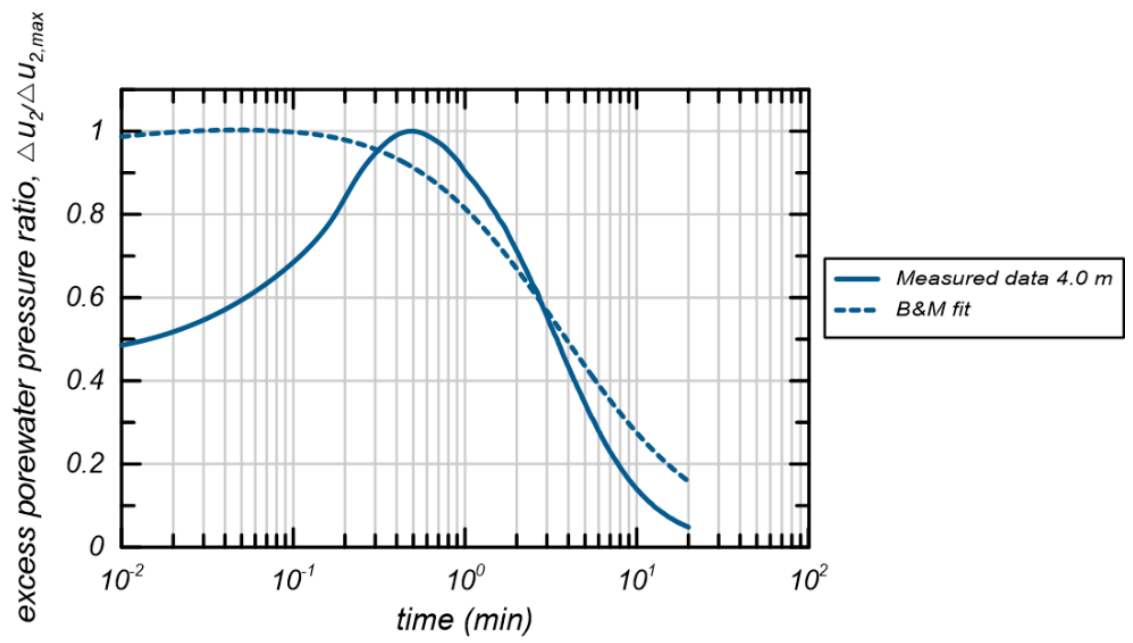

Figure 2.7: B\&M fit interpretation at $4.0 \mathrm{~m}$ depth

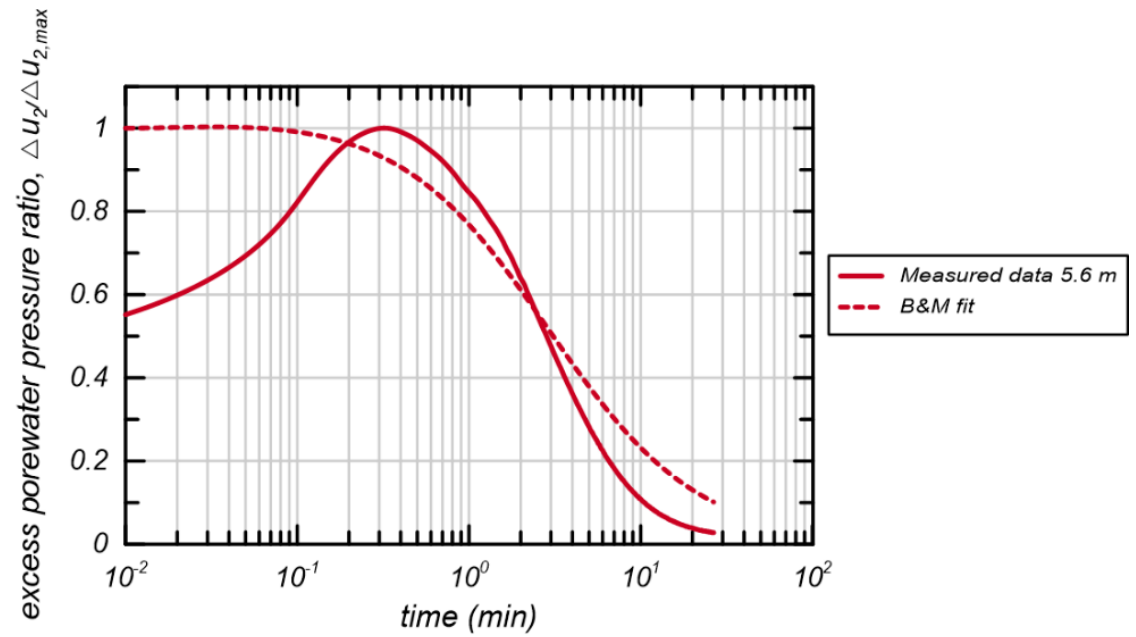

Figure 2.8: B\&M fit interpretation at $5.6 \mathrm{~m}$ depth

The interpreted $c_{h}$ values for each of the three dissipation tests are summarized in Table 2.3. The Sully interpretations differed relatively little from the T\&H interpretations. The Chai interpretations largely overestimated $c_{h}$, relative to $\mathrm{T} \& \mathrm{H}$, whereas B\&M notably underestimated $c_{h}$, relative to $\mathrm{T} \& \mathrm{H}$. 
Table 2.3: Summary of field dissipation test interpreted $c_{h}$ values

\begin{tabular}{|c|c|c|c|c|}
\hline & $\mathrm{T} \& \mathrm{H}$ & Sully & Chai & B\&M \\
\hline $\begin{array}{l}\text { Depth } \\
\text { (m) }\end{array}$ & $\begin{array}{c}\mathrm{c}_{\mathrm{h}} \\
\left(\mathrm{cm}^{2} / \mathrm{min}\right)\end{array}$ & $\begin{array}{c}\mathrm{c}_{\mathrm{h}} \\
\left(\mathrm{cm}^{2} / \mathrm{min}\right)\end{array}$ & $\begin{array}{c}\mathrm{c}_{\mathrm{h}} \\
\left(\mathrm{cm}^{2} / \mathrm{min}\right)\end{array}$ & $\begin{array}{c}\mathrm{c}_{\mathrm{h}} \\
\left(\mathrm{cm}^{2} / \mathrm{min}\right)\end{array}$ \\
\hline 2.5 & 2.5 & 2.9 & 11.3 & 0.8 \\
\hline 4.0 & 4.4 & 5.1 & 22.1 & 1.3 \\
\hline 5.6 & 5.1 & 5.8 & 23.7 & 1.4 \\
\hline
\end{tabular}

\subsection{Simulated CPTu dissipation tests}

Penetration and dissipation model

$\mathrm{CPTu}$ tests were numerically simulated via a direct axisymmetric model, as described by Moug et al. (2019), using MIT-S1 calibrated for Boston Blue Clay with geometry and boundary conditions as shown in Figure 2.9. CPTu dissipation was captured by simulating undrained penetration to steady state stress and $\Delta u$ conditions around the penetrating cone, then bringing the penetrating cone to zero penetration velocity. Once the model was static at zero penetration velocity, a new horizontal permeability $\left(k_{h}\right)$ and vertical permeability $\left(k_{v}\right)$ was assigned, and then $\Delta u$ dissipation was monitored through simulated time. 


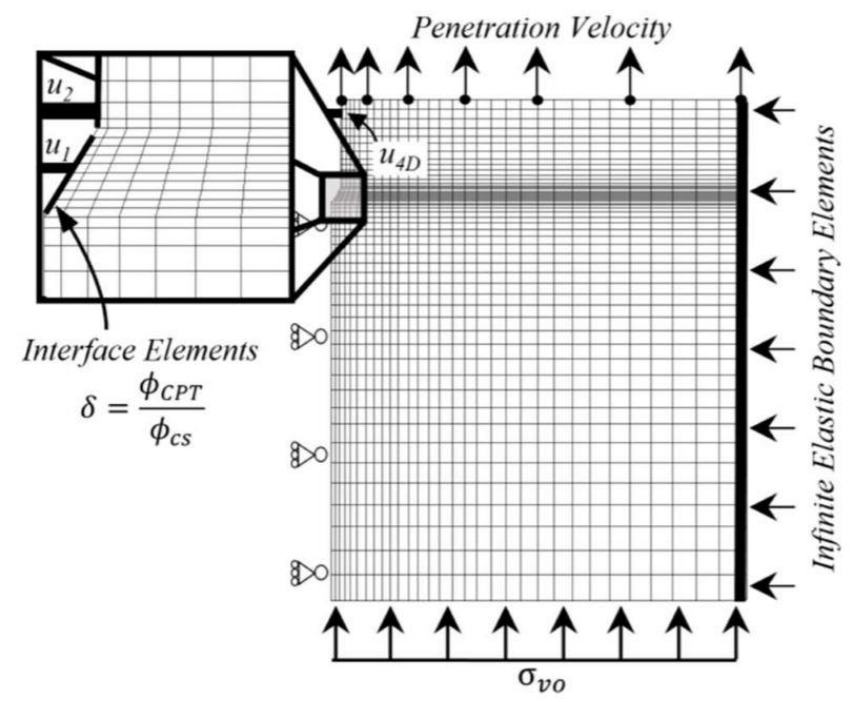

Figure 2.9: CPTu model geometry and boundary conditions

\section{Simulated results}

Dissipation of the $\Delta u$ field following undrained cone penetration in $\mathrm{BBC}$ was simulated for of OCRs - 1, 2, and 4-and hydraulic conditions- $k_{h}=k_{v}, k_{h}=2 k_{v}, k_{h}=5 k_{v}$, and $k_{h}=10 k_{v}$. The OCR range was chosen to investigate both monotonic and non-monotonic dissipation. Hydraulic conductivity anisotropies were chosen to investigate the role of $k_{h} / k_{v}$ on $u_{2}$ dissipation curves, interpretation of $c_{h}$ from $u_{2}$ dissipation curves, and the role of vertical $\Delta u$ dissipation

The simulated CPTu $u_{2}$ dissipation tests show both monotonic and non-monotonic responses. The results of simulated CPTu dissipation tests are shown in Figure 2.10. The OCR 1 simulations generated monotonic pore pressure dissipation curves, and the OCR 2 and OCR 4 simulations generated non-monotonic pore pressure dissipation curves. The magnitude of the non-monotonic bump increased with higher OCR. The ratio of hydraulic anisotropy $\left(k_{h} / k_{v}\right)$ affected the degree of non-monotonicity in the dissipation curves where, 
as the ratio of hydraulic anisotropy increased, the dissipation curves flattened and reached a lower peak pore pressure.

The magnitude of $k_{h}$ and $k_{v}$ did not affect the simulated $\mathrm{u}_{2}$ dissipation response beyond the simulated dissipation time. This is evident when comparing the responses of $k_{h}$ $=k_{v}=10^{-6} \mathrm{~m} / \mathrm{s}$ and $k_{h}=k_{v}=10^{-7} \mathrm{~m} / \mathrm{s}$; the simulated $u_{2}$ dissipation curves are shifted in time by an order of magnitude that reflects the order of magnitude change in hydraulic conductivity. For both OCR 2 and OCR 4 two hydraulically isotropic cases were simulated - the first case with $k_{h}=k_{v}=10^{-6} \mathrm{~m} / \mathrm{s}$ and the second case with $k_{h}=k_{v}=10^{-7}$ $\mathrm{m} / \mathrm{s}$. For OCR 2 and OCR 4 each of these isotropic cases generated the same peak pore pressure. The first case, corresponding to higher hydraulic conductivity (an order of magnitude higher), reached that peak pore pressure in approximately one-tenth of the time required for the second case to reach peak pore pressure. So, the magnitudes of the generated pore pressures were not sensitive to the magnitudes of the assigned hydraulic conductivities, but the time required to reach a pore pressure value of interest (e.g. peak pore pressure or pore pressure at $50 \%$ dissipation) is inversely proportional to the magnitude of the assigned hydraulic conductivities. This allowed simulations to be performed in reasonable simulation times by scaling hydraulic conductivities up to large magnitudes (relative to typical in-situ values) without distorting the dissipation behavior.

The role of $k_{h} / k_{v}$ was investigated by performing dissipation simulations for cases with $k_{v}$ being held constant and $k_{h}$ increased to $2 k_{v}, 5 k_{v}$, and $10 k_{v}$. The dissipation curves for these three hydraulically anisotropic cases are shown for OCR 1, 2, and 4 in Figure 2.10 along with the cases where $k_{h}=k_{v}$. 
Comparing the $u_{2}$ dissipation curves and $t_{50}$ from $k_{h}=k_{v}=10^{-6} \mathrm{~m} / \mathrm{s}$ and $k_{h}=10 k_{v}=10^{-6} \mathrm{~m} / \mathrm{s}$ provides insight into the role of vertical $\Delta u$ migration. For all OCR cases, the $t_{50}$ from the case where $k_{h}=k_{v}$ is smaller than the $t_{50}$ from $k_{h}=10 k_{v}$. Essentially, reducing $k_{v}$ while keeping $k_{h}$ the same results in slower dissipation times. This indicates that vertical $\Delta u$ does contribute to $u_{2}$ dissipation for both monotonic and non-monotonic dissipation tests. The effect of vertical $\Delta u$ dissipation on $c_{h}$ interpretation will be explored in the following sections. 


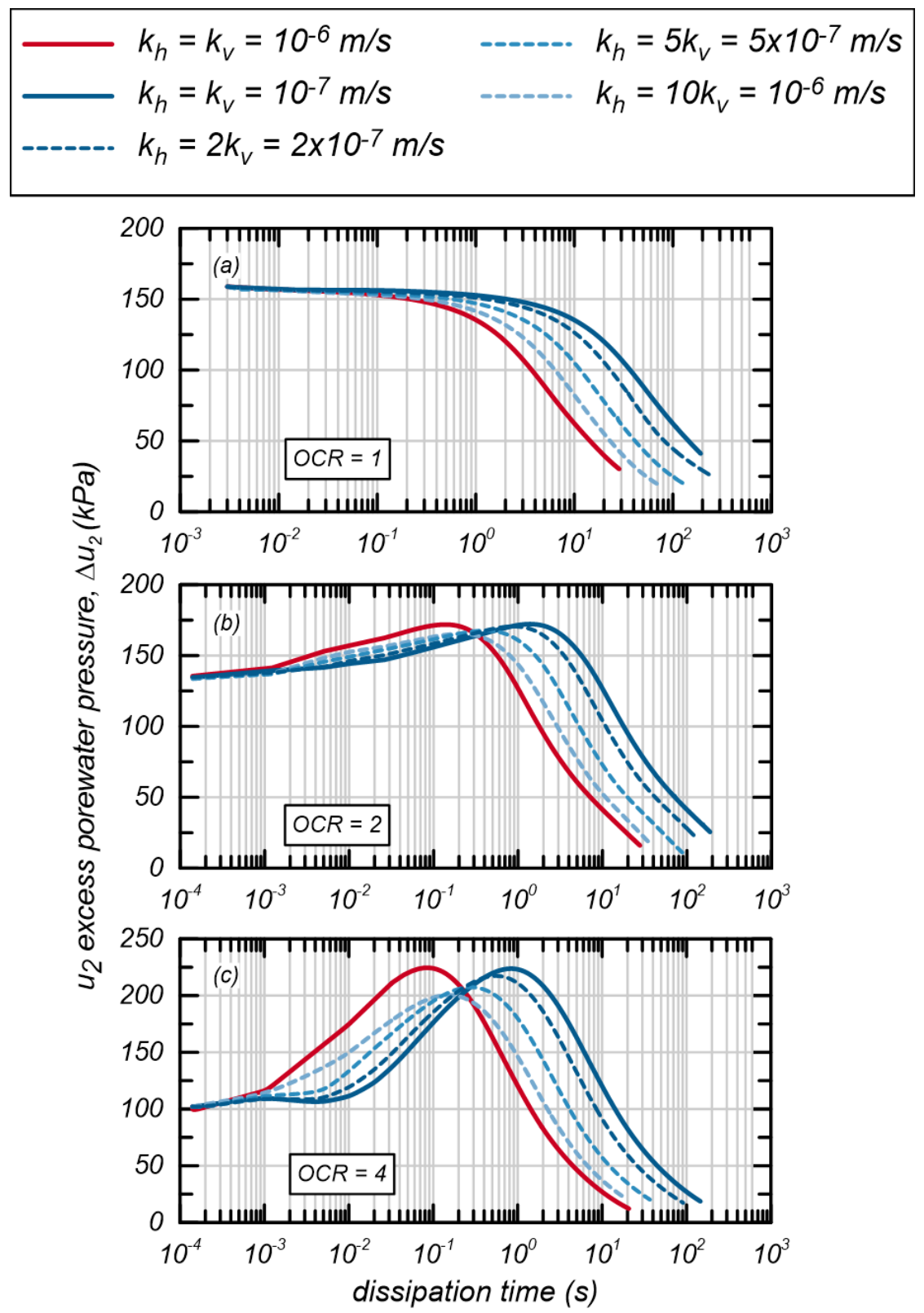

Figure 2.10: Excess pore pressure for OCR values 1, 2, and 4

\section{Interpretation of simulated CPTu tests}

The simulated dissipation tests shown in Figure 2.10 were interpreted using the four methods described previously-T\&H, Chai, Sully, and B\&M. The interpreted radial coefficient of consolidation values $c_{h \text {,interp }}$, are compared with the assigned model values, 
$c_{h, \text { model }}$, which were calculated according to Equation 2.7 using defined model parameters $k_{h}$ and constrained modulus, $D$.

$$
c_{h}=\frac{D k_{h}}{\gamma_{w}}
$$

$k_{h}$ is assigned directly as a model input; $D$ is calculated, according to Equation 2.8, from the MIT-S1 limiting compression curve shown in Figure 2.11. The MIT-S1 limiting compression curve is analogous to a normal consolidation curve for clays and is linear in $\log$-log space for void ratio over effective stress. Although the initial conditions for OCR $=2$ and 4 would be left of the limiting compression curve in Figure 2.11, the $D$ values were estimated for the equivalent position on the limiting compression curve for the same void ratio. The underlying assumption for this is that void ratio does not change during undrained penetration, and that cone penetration loading brings the condition at the cone to normally consolidated conditions.

$$
D=\frac{\Delta \sigma_{v}}{\Delta \varepsilon_{v}}=\frac{\Delta \sigma_{v}}{\Delta e / 1+e_{0}}
$$

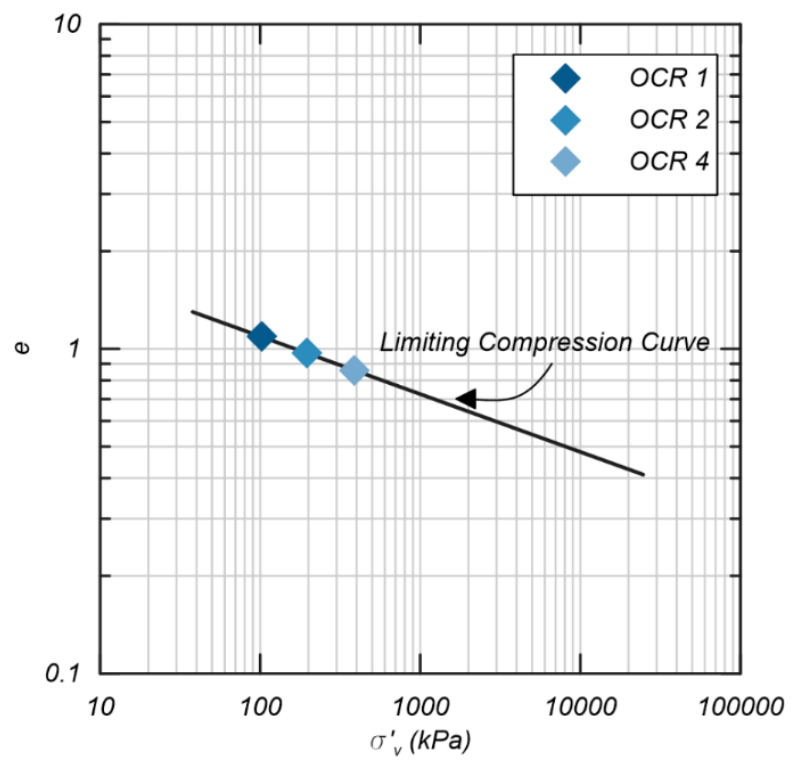

Figure 2.11: MIT-S1 limiting compression curve 


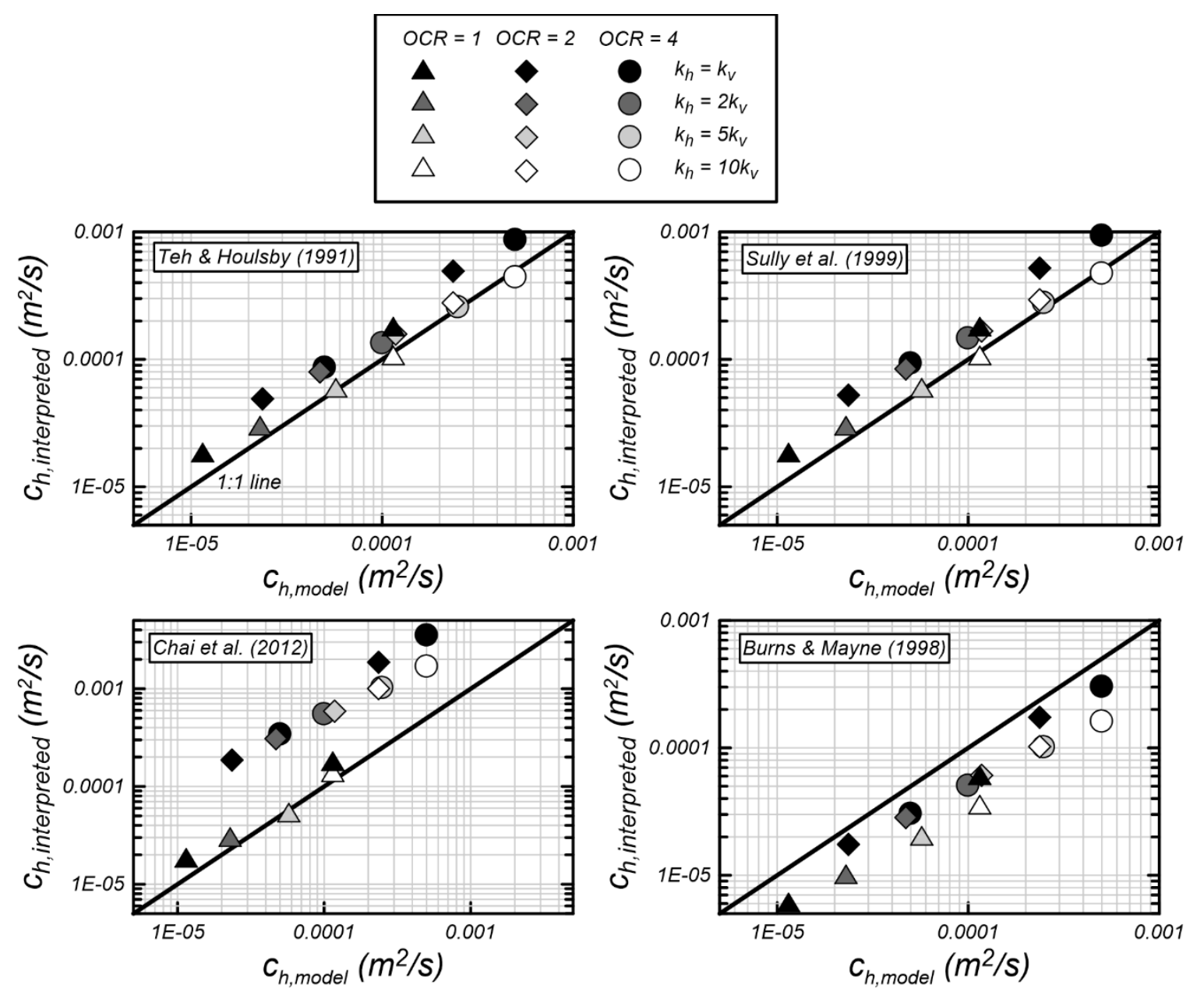

Figure 2.12: $c_{h, \text { interp }}$ vs. $c_{h, \text { model }}$ for the four interpretation methods

\subsection{Discussion}

\section{Comparison of interpretation methods}

As shown in Table 2.3 and Figure 2.12, interpreted $c_{h \text {,interp }}$ values from T\&H and Sully do not differ notably between the two methods. Both methods perform well for OCR $=1$, however, they tend to overestimate $c_{h}$ when OCR $=2$ or 4 . Chai et al.'s method calculates 
higher $c_{h}$ values for non-monotonic dissipation and largely over-estimates $c_{h, \text { model }}$, and Burns \& Mayne's method consistently estimates lower $c_{h}$ values than $c_{h \text {,model }}$.

Comparison of the results is also shown in Figure 2.13, where $c_{h, \text { interp }}$ is normalized by the $c_{h \text {,model }}$ values. T\&H and Sully estimate the $c_{h, \text { model }}$ values with similar accuracy for all simulations; they perform better when the anisotropy ratio $\left(k_{h} / k_{v}\right)$ is larger. Chai interpretations are equal to $\mathrm{T} \& \mathrm{H}$ and Sully interpretations for OCR 1 simulations, which exhibit monotonic behavior. However, for OCR greater than 1, Chai interpretations tend to overestimate $c_{h \text {,model }}$ values. In general, Chai interpretations are closer to $c_{h \text {,model }}$ values when the anisotropy ratio is larger. B\&M interpretations consistently underestimate $c_{h \text {,model }}$ values, but they are not as sensitive to OCR as Chai interpretations. For all OCRs, B\&M estimates were closest to $c_{h \text {,model }}$ values for the hydraulically isotropic simulations.

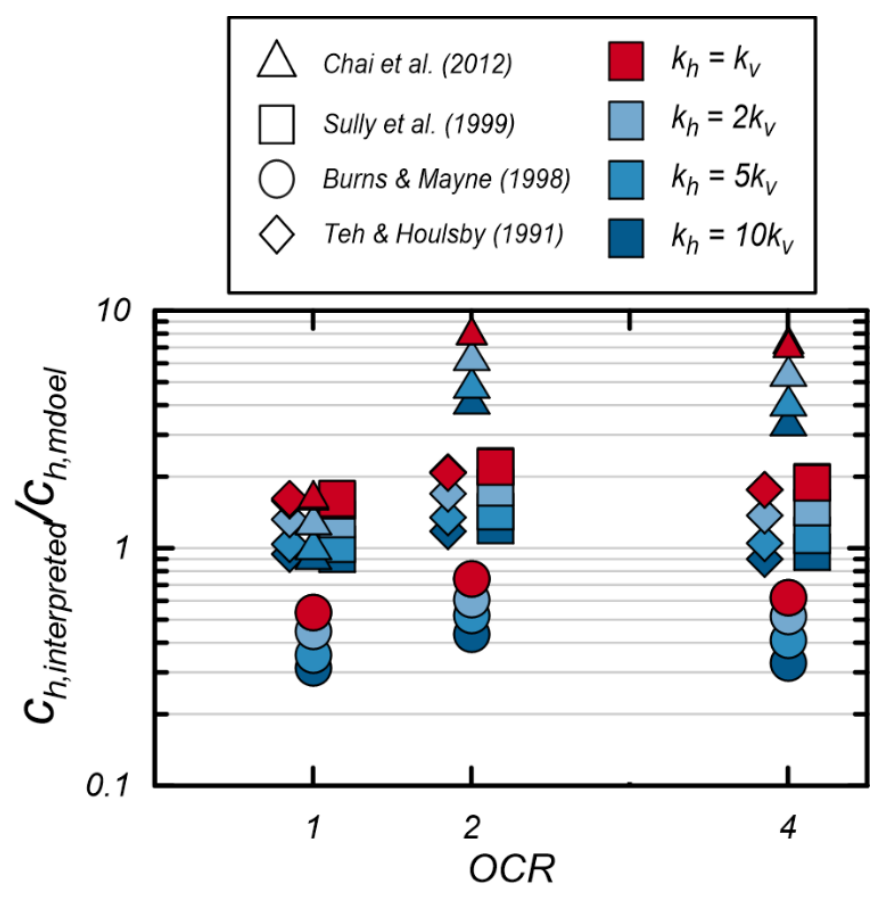

Figure 2.13: Comparison of interpreted $c_{h}$ values to model $c_{h}$ values using different methods 


\section{Role of vertical pore pressure migration}

Figures 2.10(a)-(c) each include dissipation curves for three hydraulically anisotropic simulations. For these cases, $k_{v}$ was held constant and $k_{h}$ was increased to $2 k_{v}$, $5 k_{v}$, and $10 k_{v}$. As $k_{h}$ increased, the dissipation curves shifted from the isotropic case with $k_{h}$ $=k_{v}=10^{-7} \mathrm{~m} / \mathrm{s}$ toward the isotropic case with $k_{h}=k_{v}=10^{-6} \mathrm{~m} / \mathrm{s}$.

As illustrated by the case where $k_{h}=10 k_{v}=10^{-6} \mathrm{~m} / \mathrm{s}$, even for a large hydraulic anisotropy ratio, $k_{h}$ did not completely obscure the influence of $k_{v}$. When comparing the dissipation curves for $k_{h}=k_{v}=10^{-6} \mathrm{~m} / \mathrm{s}$ and $k_{h}=10 k_{v}=10^{-6} \mathrm{~m} / \mathrm{s}$, current understanding of CPTu dissipation, where pore pressure migration in the horizontal direction dominates, indicates that these curves should generally overlap. However, Figures 2.10(a)-(c) show that the case where $k_{h}=k_{v}=10^{-6} \mathrm{~m} / \mathrm{s}$ dissipates more quickly than $k_{h}=10 k_{v}=10^{-6} \mathrm{~m} / \mathrm{s}$. This indicates that vertical pore pressure migration does contribute to $\mathrm{CPTu}$ dissipation tests, and interpretation of dissipation as occurring solely horizontally is not a strictly correct assumption.

The hydraulic anisotropy ratio especially affected the non-monotonic portion of the dissipation curves. As shown in Figures 2.10(b) and (c) as the ratio of anisotropy increased, the degree of non-monotonicity decreased. It is reasonable that the non-monotonic portion of dissipation would be especially sensitive to both horizontal and vertical hydraulic conductivities given that shear-induced vertical pore pressure migration is one of the primary causes of non-monotonic dissipation behavior.

Since the simulated dissipation tests indicate that vertical pore pressure migration takes place, it is reasonable that vertical pore pressure migration occurred in the field- 
measured dissipation tests as well. Moreover, the relationships between interpreted $c_{h}$ values from Sully, Chai, and B\&M, relative to T\&H were consistent between fieldmeasured and simulated dissipation tests. This pattern supports the notion that the relationship between interpreted and true simulation $c_{h}$ values is analogous to the relationship between interpreted and true field $c_{h}$ values. The simulated results indicate that $c_{h}$ at the field site was likely most-reasonably represented by the Teh \& Houlsby interpretation; however, these values of $c_{h}$ are likely slight over-estimates of actual values due to the non-monotonic response and contribution of vertical pore pressure migration.

\subsection{Conclusion}

This paper summarizes interpretation of monotonic and non-monotonic dissipation tests from tests that were simulated with a direct axisymmetric cone penetration model and measured in a low-plasticity silt site in Portland, OR.

Coefficient of consolidation values were interpreted from piezocone dissipation tests using published interpretation methods for monotonic and non-monotonic dissipation tests. T\&H and Sully yielded insignificantly different results. Chai calculated significantly larger $c_{h}$ values than $\mathrm{T} \& \mathrm{H}$ and Sully for non-monotonic dissipation. B\&M $c_{h}$ estimates were notably lower than $\mathrm{T} \& \mathrm{H}$ and Sully. These results suggest that, of the existing

methods, T\&H most reasonably interprets $c_{h}$ for monotonic and non-monotonic tests and that it performs better for cases with strongly anisotropic hydraulic conductivities, in which vertical pore pressure migration is limited.

Numerical CPTU simulations were performed with MIT-S1 calibrated for Boston Blue Clay behavior. Simulations were performed for soil with OCR =1, 2, and 4 and with 
hydraulic conductivity anisotropies $\left(k_{h} / k_{v}\right)$ of $1,2,5$, and 10 . The simulated results show that vertical pore pressure migration affects the CPTu response for all simulated $k_{h} / k_{v}$ values. These results suggest that further research should be performed to incorporate the contribution of vertical pore pressure migration into interpretation of coefficient of consolidation. 
Chapter 3 (Linear Elastic Finite-Element Remeshing Algorithm)

\subsection{Introduction}

Many aspects of geotechnical engineering involve penetration into soil, including the cone penetration test (CPT) which measures a nearly continuous data profile as a cone is advanced through the soil profile. Figure 3.1 shows an example of CPT-measured cone tip resistance, sleeve friction, and pore water pressure (at the $u_{2}$ position) data profiles. These data are interpreted to estimate engineering soil properties or soil type. However, existing interpretation methods are predominantly empirically based and are therefore limited to a narrow range of soil types and conditions.
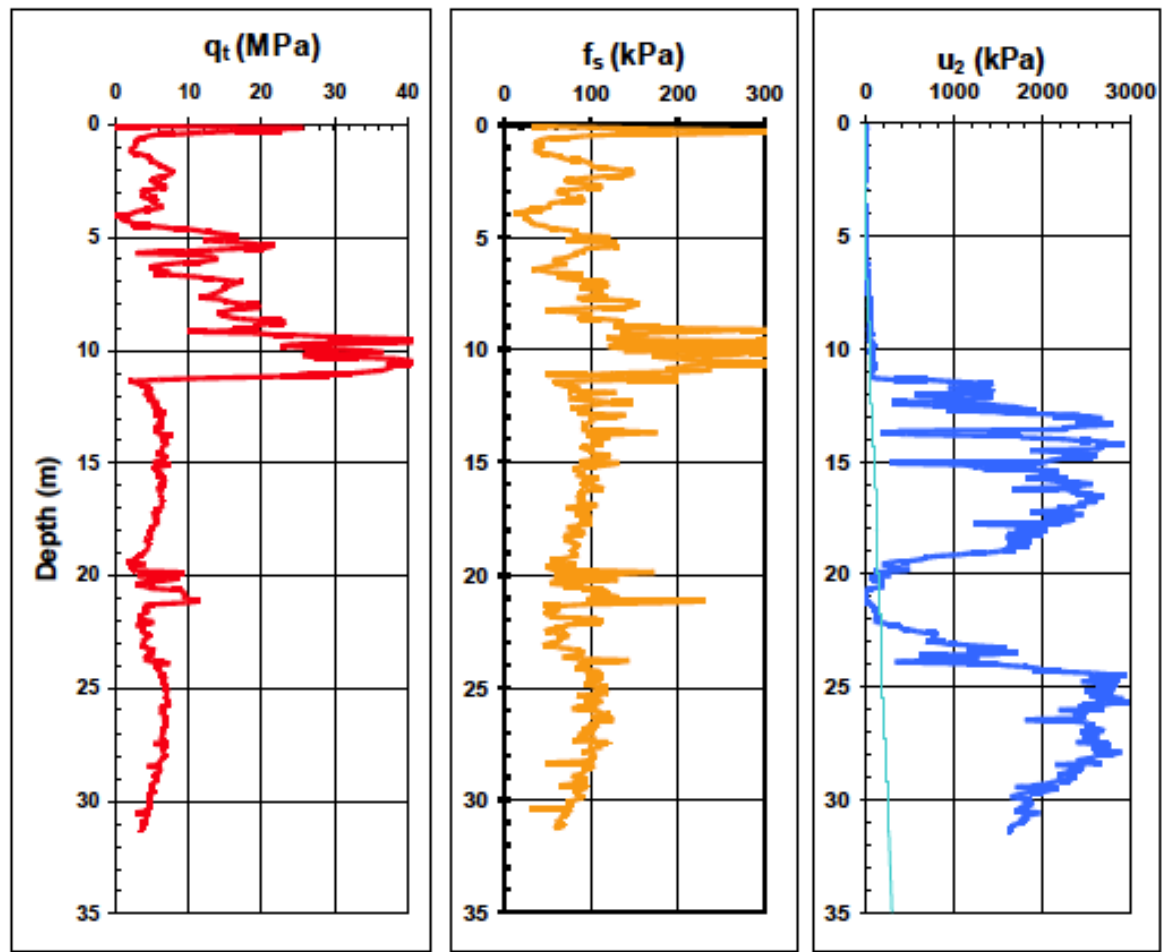

Figure 3.1: Example of CPT-measured site profile

Cone penetration simulations have led to more reliable, theory-based characterization methods of engineering properties. Advanced numerical analysis of 29 
penetration is challenging due to large deformations around the penetrometer that lead to severe element distortion and numerical instability. Large deformations have been overcome with Arbitrary Lagrangian Eulerian (ALE) algorithms where deformed model geometry (from Lagrangian calculations) is remeshed to a less deformed geometry, then model properties are remapped from the old mesh onto the new mesh with Eulerian calculations. A schematic of the ALE algorithm with a cone penetration model is illustrated in Figure 3.2. Published numerical analyses of cone penetration are still limited by either (a) using simple soil models that idealize soil behavior, (b) not capturing changing conditions with depth, or (c) idealizing soil as isotropic and uniform. Advancing CPT interpretation methods requires simulations of full penetration conditions with depth and with an advanced soil model.

\section{Lagrangian step}

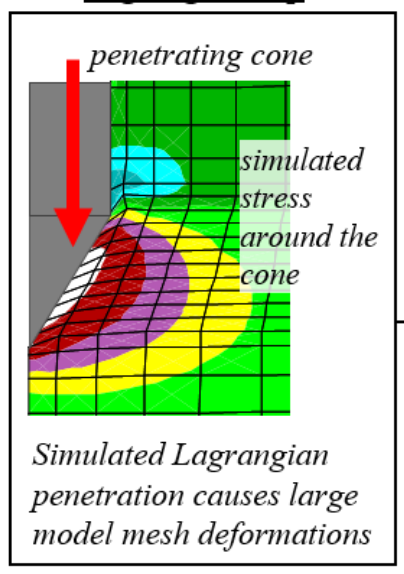

Remeshing step

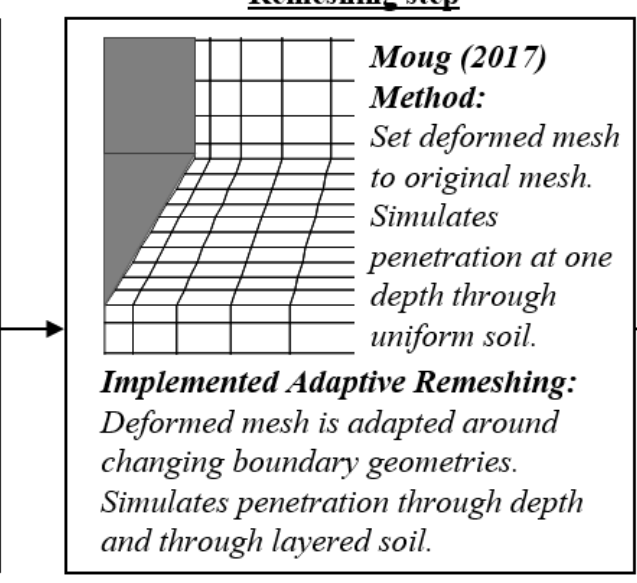

cycle to advance simulated penetration

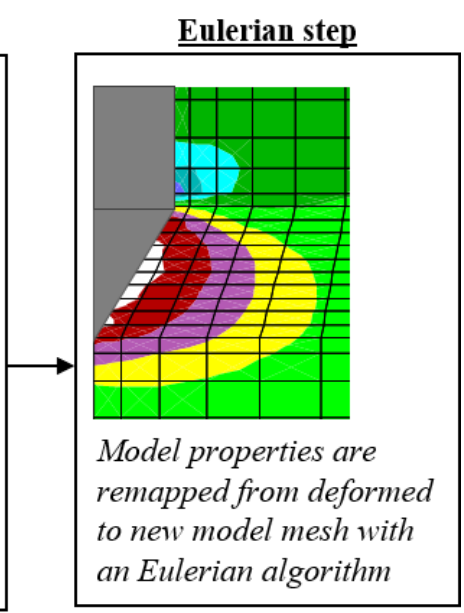

an Eulerian algorithm

Figure 3.2: Schematic illustrating the ALE algorithm with adaptive remeshing

Moug (2017) presented a steady-state, ALE numerical model for simulating cone penetration at a single depth using the MIT-S1 constitutive model. MIT-S1 is a complex 
constitutive model that captures clayey and silty behavior well, including anisotropic loading of clay, which is especially important because of the complex anisotropic stress conditions that exist around the cone (Moug, et al. 2019). This numerical model accurately reflects complex soil behavior.

However, the model is limited to simulating conditions at a single depth and unable to model behavior over a range of depths as the cone advances through a soil profile. Also, the model is limited to modeling conditions within a uniform soil and unable to represent non-uniform soils, such as an interlayered soil profile. These limitations result from the implemented remeshing step, which resets the deformed mesh to the original undeformed mesh before performing Eulerian remapping calculations.

To overcome these limitations, an algorithm for an adaptive remeshing step is presented. In this remeshing step boundary nodes (e.g. nodes that delineate soil-structure or soil unit interfaces) are tracked, and interior node positions are systematically adapted based on linear-elastic relationships to boundary node displacements. This chapter presents the approach for adaptive remeshing, its verification, describes its implementation with the FLAC cone penetration model, and proposes future work for its application.

\subsection{Adaptive remeshing approach}

This adaptive remeshing step is formulated as an axisymmetric, linear elastic finite-element problem with known displacements at the boundary nodes of the grid: the displacement of the interior nodes is determined based on linear-elastic relationships to displacement of the boundary nodes. The FLAC model grid node coordinates prior to deformation are used to define the finite-element model geometry, where each FLAC zone is treated as an element. 
From this geometry and assigned material stiffness properties, the axisymmetric grid's stiffness matrix is defined, according to standard axisymmetric finite-element equations. Note that these linear elastic material properties are assigned for the adaptive remeshing only and do not represent actual soil properties. The FLAC grid is represented by the linear system: $K \epsilon=\sigma$, where $K$ is the stiffness matrix, $\epsilon$ is a vector of radial and axial strains at each node, and $\sigma$ is a vector of radial and axial stresses at each node.

This linear system presents an inhomogeneous strong boundary condition problem in which $\epsilon$ is partially known (at the boundary nodes) and partially unknown (at the interior nodes), and similarly $\sigma$ is partially known (zero at the interior nodes) and partially unknown (at the boundary nodes). The solution for this system is obtained by applying the algorithm described by Bangerth (2013).

After solution, the strains at the interior nodes are known, from which the displacements at the interior nodes are calculated. The calculated displacements at the interior nodes are used to calculate their adapted coordinates. The adapted boundary nodes and interior nodes form the remeshed grid. The coordinates of this remeshed grid are read by FLAC to proceed with the Eulerian remapping step of the ALE cycle.

To illustrate the solution algorithm, consider solving the equation $K x=p$ for the example finite-element mesh in Figure 3.3, where $K$ is the system's stiffness matrix, $x$ is a vector containing the nodal displacements, and $p$ is a vector containing the nodal forces. Assume that the displacements at the outer nodes (i.e. nodes 0, 2, 3, 4, 7, 8, and 9) are known, and the displacements at the interior nodes (i.e. nodes 1, 5, and 6) are unknown. 
Conversely, the forces at the exterior nodes are unknown, and the forces at the interior nodes are known to be zero.

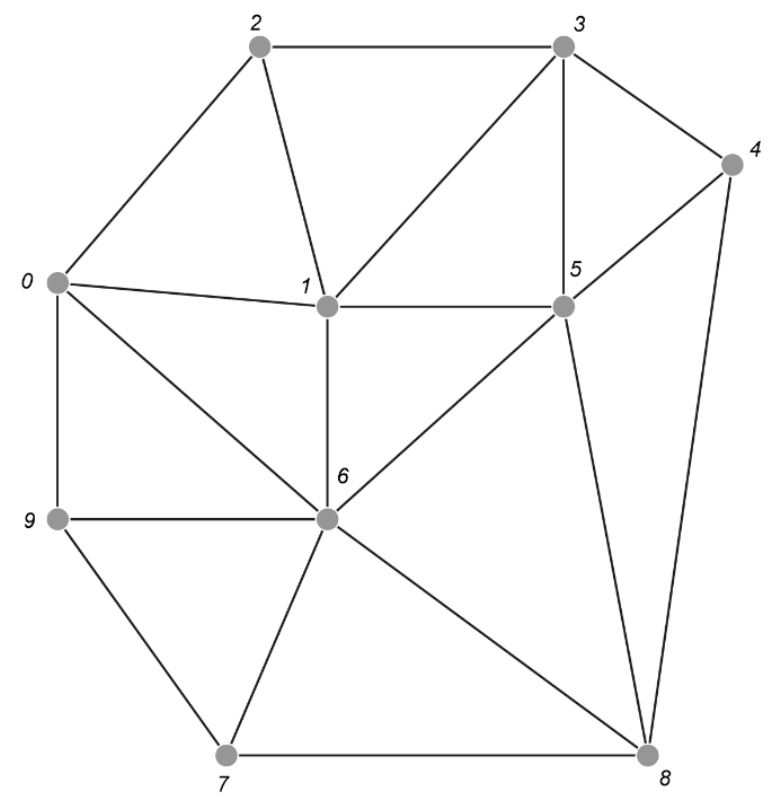

Figure 3.3: Example finite-element mesh with 10 nodes

Let:

$$
\begin{gathered}
g\left(n_{0}\right) \\
0 \\
g\left(n_{2}\right) \\
g\left(n_{3}\right) \\
g\left(n_{4}\right), \text { where } g\left(n_{i}\right)=x_{i} . \\
0 \\
0 \\
g\left(n_{7}\right) \\
g\left(n_{8}\right) \\
\left.g\left(n_{9}\right)\right\rfloor
\end{gathered}
$$

The system to be solved is represented by equation 3.1: 


$\left.\left.\begin{array}{llllllllllll}k_{00} & k_{01} & k_{02} & k_{03} & k_{04} & k_{05} & k_{06} & k_{07} & k_{08} & k_{09} & x_{0} & p_{0} \\ k_{10} & k_{11} & k_{12} & k_{13} & k_{14} & k_{15} & k_{16} & k_{17} & k_{18} & k_{19} & x_{1} & p_{1} \\ k_{20} & k_{21} & k_{22} & k_{23} & k_{24} & k_{25} & k_{26} & k_{27} & k_{28} & k_{29} & x_{2} & p_{2} \\ k_{30} & k_{31} & k_{32} & k_{33} & k_{34} & k_{35} & k_{36} & k_{37} & k_{38} & k_{39} & x_{3} & p_{3} \\ k_{40} & k_{41} & k_{42} & k_{43} & k_{44} & k_{45} & k_{46} & k_{47} & k_{48} & k_{49} & x_{4} \\ k_{50} & k_{51} & k_{52} & k_{53} & k_{54} & k_{55} & k_{56} & k_{57} & k_{58} & k_{59} & x_{5} \\ k_{60} & k_{61} & k_{62} & k_{63} & k_{64} & k_{65} & k_{66} & k_{67} & k_{68} & k_{69} & x_{6} & p_{5} \\ k_{6} \\ k_{70} & k_{71} & k_{72} & k_{73} & k_{74} & k_{75} & k_{76} & k_{77} & k_{78} & k_{79} & x_{7} & p_{7} \\ k_{80} & k_{81} & k_{82} & k_{83} & k_{84} & k_{85} & k_{86} & k_{87} & k_{88} & k_{89} \\ k_{90} & k_{91} & k_{92} & k_{93} & k_{94} & k_{95} & k_{96} & k_{97} & k_{98} & k_{99}\end{array}\right\rfloor \begin{array}{l}p_{8} \\ \left.x_{9}\right\rfloor \\ p_{9}\end{array}\right\rfloor$.

Then, an equivalent solution of equation 3.1 is obtained by using standard methods to bring unknowns to the left side and to solve the system in equation 3.2:

$$
\left.\begin{array}{c}
p_{1^{-}} \sum_{i \in\{0,2,3,4,7,8,9\}} k_{l i} g\left(n_{i}\right) \\
{\left[\begin{array}{lll}
k_{11} & k_{15} & k_{16} \\
k_{51} & k_{55} & k_{56} \\
k_{61} & k_{65} & k_{66}
\end{array}\right]\left[\begin{array}{l}
x_{1} \\
x_{5} \\
x_{6}
\end{array}\right]=p_{5^{-}} \sum_{i \in\{0,2,3,4,7,8,9\}} k_{5 i} g\left(n_{i}\right)} \\
\mathrm{L}^{p_{6^{-}}} \sum_{i \in\{0,2,3,4,7,8,9\}} k_{6 i} g\left(n_{i}\right)
\end{array}\right]
$$

\subsection{Verification of adaptive remeshing algorithm}

The linear elastic finite-element adaptive remeshing algorithm was implemented in Python. To verify the implemented finite-element solution, two linear elastic problemsunconfined axial compression and radial compression—with Poisson's ratio, $v,=0.3$ and bulk modulus, $K_{b u l k},=10000 \mathrm{kPa}$ were solved via FLAC and the finite-element solution, and the solutions were compared. Each of the deformed grids are plotted together in Figures 3.4 and 3.5 for unconfined axial compression and radial compression, respectively. As shown in Figures 3.4 and 3.5 the solutions exhibit a high degree of agreement, which indicates that the finite-element solution is properly implemented. 
Note that the FLAC grid consists of rectangular zones defined by four nodes, but the finite-element formulation divides each of these zones into four triangles whose common vertex is in the middle of the rectangular zone. So, the finite-element representation of one FLAC zone, defined by four points, is defined by five points. This is the reason for the extra nodes within the FLAC zones in Figures 4 and 5.
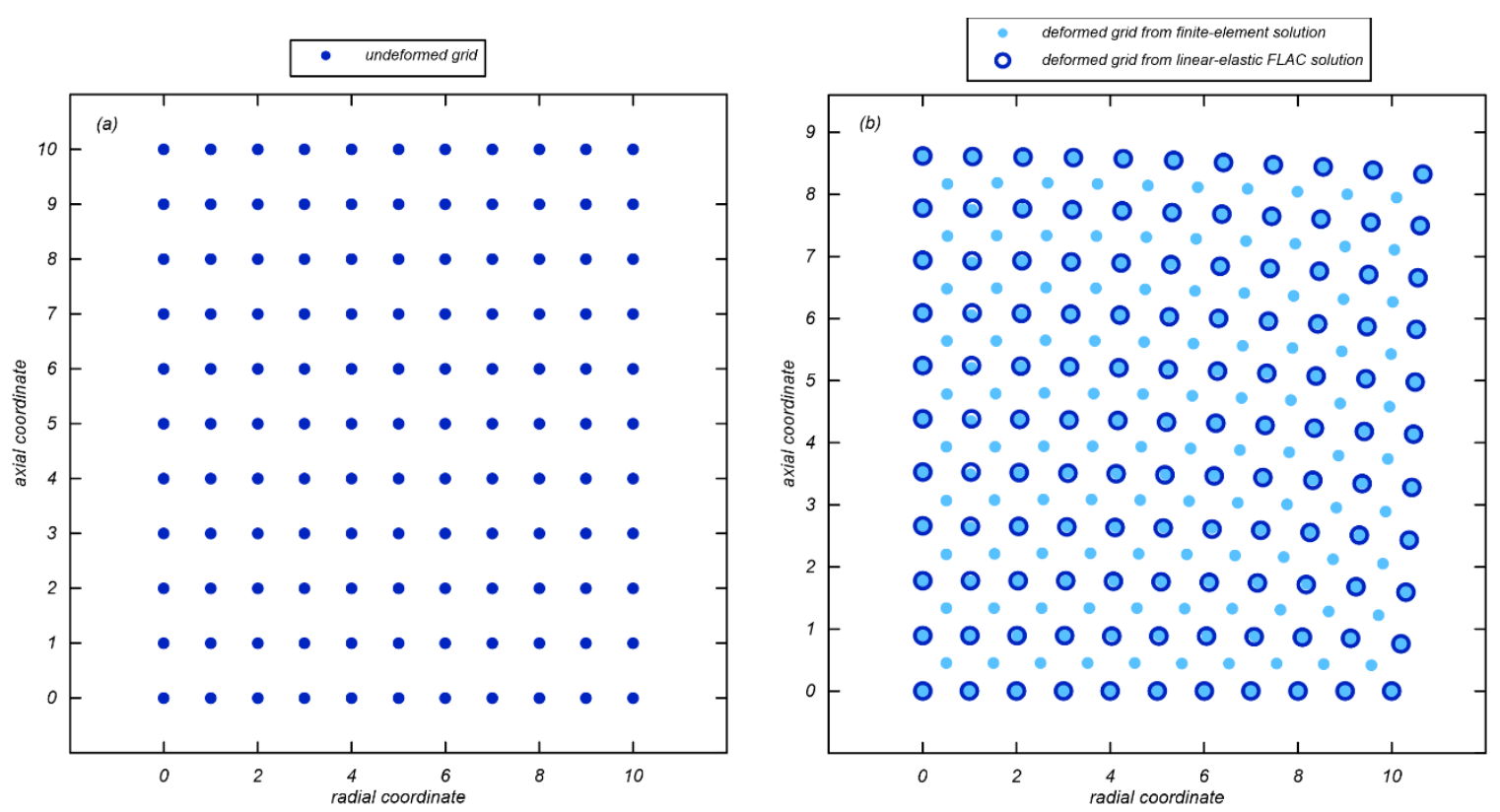

Figure 3.4: Comparison of undeformed grid coordinates and deformed (by unconfined axial compression) grid coordinates, obtained by solution in FLAC and the remeshing finite-element solution 

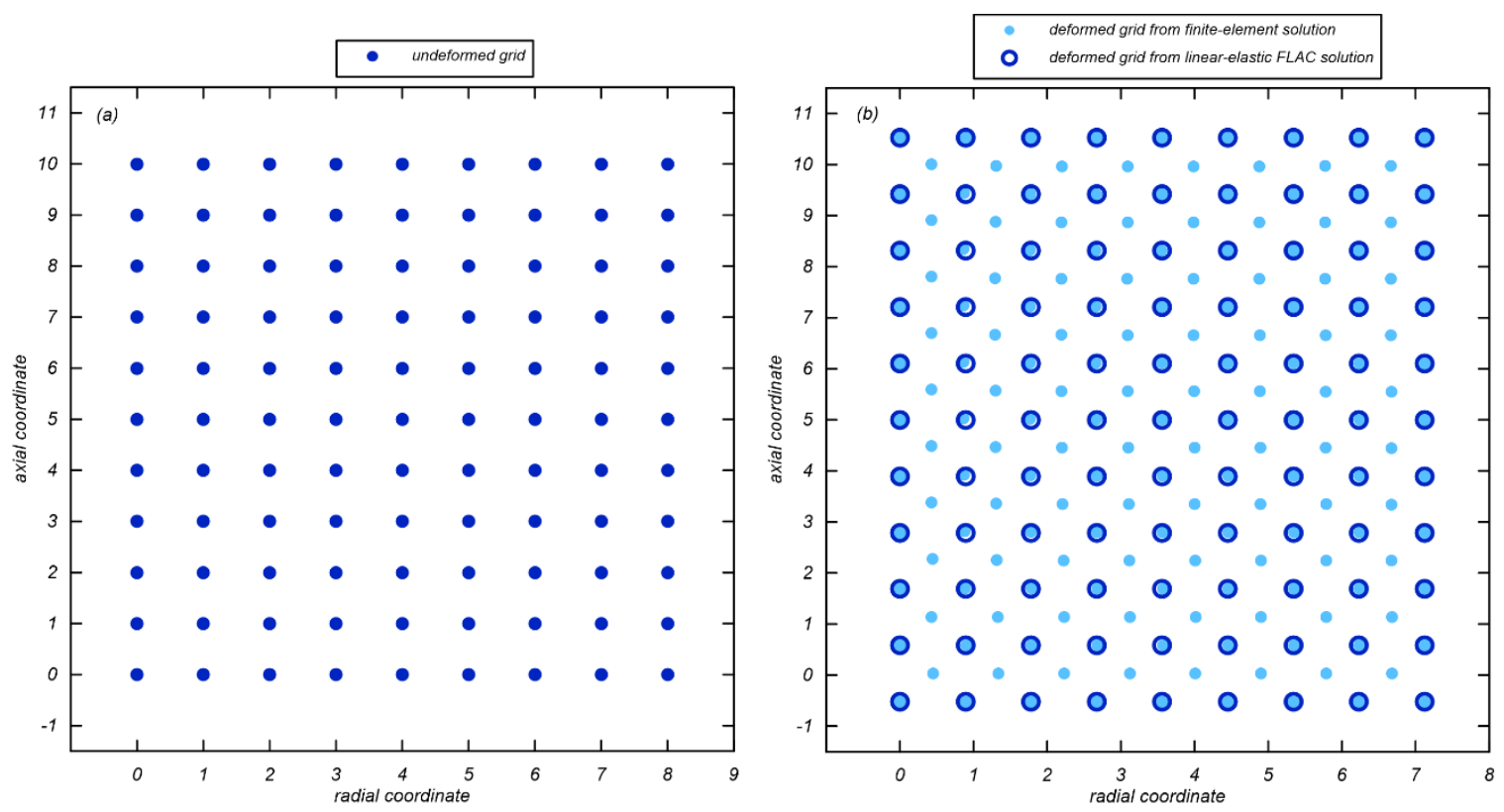

Figure 3.5: Comparison of undeformed grid coordinates and deformed (by radial compression) grid coordinates, obtained by solution in FLAC and the remeshing finiteelement solution

\subsection{Implementation with FLAC cone penetration model}

The adaptive remeshing algorithm incorporates into the FLAC direct cone penetration model presented in Moug (2017). The direct penetration model with an ALE algorithm in Moug (2017) follows the steps of (1) simulate direct penetration for a set distance - now the geometry is considered deformed due to Lagrangian deformations, (2) reset gridpoints to the initial, undeformed geometry, and (3) remap model properties from the deformed to undeformed geometry with an Eulerian convective algorithm. This model simulates cone penetration by holding the cone at one point in the soil column, and simulating soil as flowing up past the stationary cone. The outcome is a steady state cone penetration model that simulates the stress, porewater pressure, and strain around a cone at one point in the soil column. 
The adaptive remeshing algorithm is implemented into the original algorithm instead of step (2). The adaptive remeshing algorithm determines the adjustments to deformed gridpoints based on the deformations at boundary gridpoints. This will allow cone penetration to be simulated as a cone penetrating through the soil column, and across material boundaries (i.e., soil layers).

This implementation requires running the Python-implemented adaptive remeshing algorithm along with the FLAC cone penetration model. The “Axisymmetric_Displacement_Solution.py" file should be located in the same folder as the cone penetration model is run from. The cone penetration model with adaptive remeshing is run with the following steps:

(i) Run the Python executable file "Axisymmetric_Displacement_Solution.py" from Spyder.

(ii) Run the cone penetration model executable "CPT_ALE_adapt.fis" from a FLAC project.

These two steps should run the new cone penetration model that has been adjusted to integrate adaptable remeshing. The pseudo algorithm is outlined as:

- Initialize model geometry and initial conditions

- Solve to ensure the model is at static conditions

- While time is less than total solve time:

- Write "undeformed" model coordinates to a ttxt file "write_coordinates.txt"

- Simulate cone penetration for a set penetration distance 
○ Write "deformed" model coordinates to a txt file "new_boundary_coordinates.txt". This file is written to have a column with a flag $=1$. This file is being continuously checked in the Python routine. If flag $=0$, Python continues to check; if flag $=1$, Python carries out the adaptive remeshing routine.

- Pause FLAC execution to let the Python script execute.

Note: the amount of time of the pause will depend on the computer speed and size of the model. We have found 20 seconds to be sufficient in initial simulations.

○ Python solves for internal gridpoint displacements based on "new_boundary_coordinates.txt" and assigned linear elastic material properties.

○ Python outputs "adapted_coordinates.fis" file, and FLAC assigns new geometry from these coordinates.

- Remap model properties from deformed to adapted model geometry with Eulerian algorithms (Moug 2017).

\subsection{Conclusions \& Next Steps}

This chapter describes the implementation of an adaptive remeshing scheme for an ALE algorithm. The algorithm is developed to be implemented with a direct axisymmetric cone penetration model in FLAC. The adaptive remeshing algorithm was validated by comparing its results of solving gridpoint displacements with results from a linear elastic solution in FLAC. 
The next objective is to implement the adaptive remeshing approach in simulating cone penetration and validate this model. After validation, the model can be applied to model continuous cone penetration. A particularly interesting application of the new model would be modeling cone penetration through an interlayered soil profile to investigate thinlayer effects and behavior at and across soil layer interfaces. 


\section{Chapter 4 (Conclusions and Future Work)}

This thesis presented analysis of CPTu dissipation tests and their interpretation. Both field and simulated dissipation tests were considered. Additionally, the implementation and verification of a linear elastic finite-element adaptive remeshing algorithm that is to be implemented with the Moug (2017) ALE model were described.

Chapter 2 of this thesis analyzed CPTu dissipation responses from field-measured and numerically simulated dissipation tests and their interpretation, according to four published methods. The accuracy of these methods in interpreting assigned model properties was examined under various conditions of vertical and horizontal hydraulic conductivities and OCR. The roles of vertical and horizontal pore pressure migration and non-monotonicity in dissipation behavior and interpretation were explored.

This analysis indicated that existing methods of interpreting coefficient of consolidation from dissipation tests fall short in two areas-improper interpretation of nonmonotonic dissipation and inaccurate neglect of the role of vertical pore pressure migration during dissipation testing. Methods of accounting for non-monotonicity do not seem to have sound theoretical and mechanical bases. Also, it seems that treating dissipation as a solely horizontal problem is not an accurate assumption.

Future continuation of this work should include further investigation of interpretation of coefficient of consolidation from non-monotonic dissipation data and consideration of both vertical and horizontal pore pressure migration during dissipation testing. Non-monotonicity and vertical pore pressure migration should be studied to better understand their roles in dissipation and their underlying mechanisms. An approach to 
interpret coefficient of consolidation from dissipation tests that properly accounts for nonmonotonicity and both vertical and horizontal pore pressure migration should be pursued.

Chapter 3 of this thesis described the implementation of a linear elastic finiteelement adaptive remeshing algorithm that, when integrated with the Moug (2017) model, provides a numerical scheme capable of simulating cone penetration through depth, while retaining the valuable constitutive performance of the original model. This chapter also presented verification of the implemented remeshing algorithm.

Future application of this work should include simulation of cone penetration using this adaptive remeshing step integrated with the Moug (2017) model to simulate continuous cone penetration through a soil profile. This updated model could be used to investigate cone penetration through interlayered soil profiles, including dissipation behavior in profiles consisting of layers with varying hydraulic properties. 


\section{References}

ASTM Standard D5778 -12. "Standard test method for electronic friction cone and piezocone penetration testing of soils." ASTM International, West Conshohocken, PA, 2012, https://doi.org/10.1520/D5778-12.

Bangerth, W. (2013). "Boundary Conditions Part 3b: Inhomogeneous Dirichlet Boundary Conditions." MATH 676: Finite element methods in scientific computing, https://www.math.colostate.edu/ bangerth/videos.html.

Boulanger, R. W., Idriss, I. M. (2016). “CPT-Based Liquefaction Triggering Procedure.” Journal of Geotechnical and Geoenvironmental Engineering, 142(2): 04015065.

Burns, S. E., and Mayne, P. W. (1998). "Monotonic and dilatory pore-pressure decay during piezocone tests in clay." Canadian Geotechnical Journal, 35, 1063-1073.

Chai, J., Sheng, D., Carter, J. P., and Zhu, H. (2012). "Coefficient of consolidation from non-standard piezocone dissipation curves.” Computers and Geotechnics, 41, 13-22.

Chen, B. S., Mayne, P. W (1994). "Profiling the Overconsolidation Ratio of Clays by Piezocone Tests.” Georgia Institute of Technology Internal Report 94-1.

Jamiolkowskie, M.J., Ghionna, V.N., Lancellotta, R., Pasqualini, E. (1988). “New Correlations of Penetration Tests for Design Practice." Proceedings of the First International Symposium on Penetration Testing, 263-296.

Krage, C. P., Broussard, N. S., and DeJong, J. T. (2014). "Estimating Rigidity Index Based on CPT Measurements." 3rd International Symposium on Cone Penetration, 727735 .

Mayne, P. W. (2001). "Stress-strain-strength-flow Parameters from Enhanced In-situ Tests." Proceedings, International Conference on In-Situ Measurement of Soil Properties \& Case Histories, 27-48.

Mayne, P. W. (2007). “Cone penetration testing state-of-practice.” NCHRP Project 2095, Transportation Research Board, Washington, DC

Moug, D.M. (2017). “Axisymmetric cone penetration model for sands and clays.” PhD Thesis, Department of Civil and Environmental Engineering, University of California, Davis.

Moug, D.M., Boulanger, R.W., DeJong, J.T., and Jaeger, R.A. (2019). “Axisymmetric cone penetration simulations in saturated clay." Journal of Geotechnical and Geoenvironmental Engineering, 145(4): 04019008.

Moug, D., Khosravifar, A., Preciado, M., Sorenson, K., Stokoe, K., Menq, F., Zhang, B., van Paassen, L., Kavazanjian, E., Stallings Young, E., Wang, Y (2020). "Field 
Evaluation of Microbially Induced Desaturation for Liquefaction Mitigation of Silty Soils." $17^{\text {th }}$ World Conference on Earthquake Engineering.

Preciado, A.M., Sorenson, K., Khosravifar, A., Moug, D., Stokoe, K., Menq, F., Zhang, B. (2021). "Evaluating Cyclic Loading Response of Low Plasticity Silt with Laboratory and Field Cyclic Loading Tests." Unpublished paper, Portland State University.

Robertson, P. K. (2009). "Interpretation of cone penetration tests - a unified approach." Canadian Geotechnical Journal, 46(11), 1337-1355, https://doi.org/10.1139/T09-065.

Schnaid, F., Sills, G. C., Soares, J. M., and Nyirenda, Z. (1996). "Predictions of the Coefficient of Consolidation from Piezocone Tests." Canadian Geotechnical Journal, 34, 315-327.

Sorenson, K., Preciado, A. M., Moug, D., Khosravifar, A., van Paassen, L., Kavazanjian Jr., E., Stokoe, K., Menq, F. (2021). "Field Monitoring of the Persistence of Microbially Induced Desaturation for Mitigation of Earthquake Induced Soil Liquefaction in Silty Soil.” Unpublished paper, Portland State University.

Sully, J. P., Robertson, P. K., Campanella, R. G., and Woeller, D. J. (1999). “An approach to evaluation of field CPTU dissipation data in overconsolidated fine-grained soils." Canadian Geotechnical Journal, 36, 369-381.

Teh, C. I., and Houlsby, G. T. (1991). "An analytical study of the cone penetration test in clay." Geotechnique, 41(1), 17-34.

Whittle, A. J., Sutabutr, T., Germaine, J. T., and Varney, A. (2001). "Prediction and interpretation of pore pressure dissipation for a tapered piezoprobe." Geotechnique, 51(7), 601-617. 